\title{
Options for Home Oxygen Therapy Equipment: Storage and Metering of Oxygen in the Home
}

\author{
Robert W McCoy RRT FAARC
}

\author{
Introduction \\ Evolution of Home Oxygen Equipment \\ Home Oxygen: Equipment Economic Issues \\ Oxygen Equipment: From Hospital to Home \\ Home Oxygen: Drug or Device? \\ Home Oxygen: A Mobility Solution \\ Sources of Oxygen for Home Use \\ Oxygen Produced, Stored, and Transported by a Gas Manufacturer and \\ Home Medical Equipment Supplier \\ Oxygen Produced Within the Home by Oxygen Concentrator \\ Metering Oxygen to the Patient \\ Estimate of Continuous Flow $\mathrm{F}_{\mathrm{IO}_{2}}$ From a Nasal Cannula \\ Equipment Options \\ Compressed Oxygen Cylinders \\ Liquid Oxygen Systems \\ Oxygen Concentrators \\ Intermittent-Flow Regulators \\ Oxygen Monitoring \\ Pressurized Oxygen \\ Portable Oxygen Concentrators \\ Discussion \\ Home Oxygen Prescriptions \\ Patient Assessment \\ Oxygen Metering \\ Recommendations \\ Summary
}

Home oxygen therapy equipment options have increased over the past several decades, in response to innovations in technology, economic pressure from third-party payers, and patient demands. The delivery of oxygen in the home has evolved from packaged gas systems containing $99 \%$ United States Pharmacopeia oxygen provided by continuous-flow delivery to intermittent-flow delivery, with oxygen concentrators delivering $<99 \%$ oxygen purity. The majority of published papers indicating the value of long-term oxygen therapy have been based on continuous-flow delivery of 99\% United States Pharmacopeia oxygen. The lack of research on new home oxygen therapy devices requires more clinical involvement from physician and respiratory therapist to evaluate the performance of oxygen devices used in the home to ensure the patient is provided adequate oxygenation at all activity levels. New standards of care are required to address the need to have consistent titration of long-term oxygen therapy to meet the patient's home needs at all activity levels. Consistent labeling of metering devices on home oxygen equipment will need to be developed 
by professional medical societies to be implemented by standards organizations that direct industrial manufacturers. Home oxygen therapy will need professionally trained respiratory therapists reimbursed for skills and service to ensure that patients receive optimal benefits from home oxygen equipment to improve patient outcomes and prevent complications and associated costs. Key words: oxygen; equipment; home. [Respir Care 2013;58(1):65-81. (c) 2013 Daedalus Enterprises]

\section{Introduction}

Patients requiring long-term oxygen therapy (LTOT) must have access to clinically effective home oxygen equipment that is adaptable to their needs outside the hospital. Costing less and providing for a more normal lifestyle, home oxygen therapy has evolved to a standard of care for patients experiencing chronic hypoxemia. Going beyond stationary home devices, new oxygen equipment has been developed to meet the needs both of the patient who is more mobile and of the oxygen suppliers who are struggling to respond to economic pressures from payers. It is important to keep in mind that oxygen equipment only stores or produces oxygen in the home. Oxygen is a drug that requires a prescription, an effective delivery system, therapeutic dosing, and monitoring for effective therapy. Economics and patient demands are a secondary consideration to providing effective oxygen therapy.

Oxygen therapy is the administration of oxygen at concentrations greater than ambient air, with the intent of treating or preventing the symptoms and manifestations of hypoxia (Fig. 1). ${ }^{1}$ Reviews by both Kacmarek ${ }^{2}$ and Dunne ${ }^{3}$ have provided timely updates to the current available products for LTOT. Since those reviews, in 2000 and 2009, additional products have been introduced for use in the home with manufacturers of home oxygen equipment focusing product development on both the home medical equipment (HME) provider's requirements to reduced operating expense and the patient's needs for mobility. The minimal research confirming the clinical benefits and applications of new home oxygen equipment suggests that clinicians are not driving the design of these new products.

Mr McCoy is affiliated with Valley Inspired Products, Apple Valley, Minnesota.

Mr McCoy presented a version of this paper at the 50th RESPIRATORY CARE Journal Conference, "Oxygen," held April 13-14, 2012, in San Francisco, California.

Mr McCoy has disclosed relationships with Breathe Technologies, Caire Medical, and Sequal.

Correspondence: Robert W McCoy RRT FAARC, Valley Inspired Products, 15112 Galaxie Avenue, Apple Valley MN 55124. E-mail: bmccoy@inspiredrc.com.

DOI: $10.4187 /$ respcare.01932

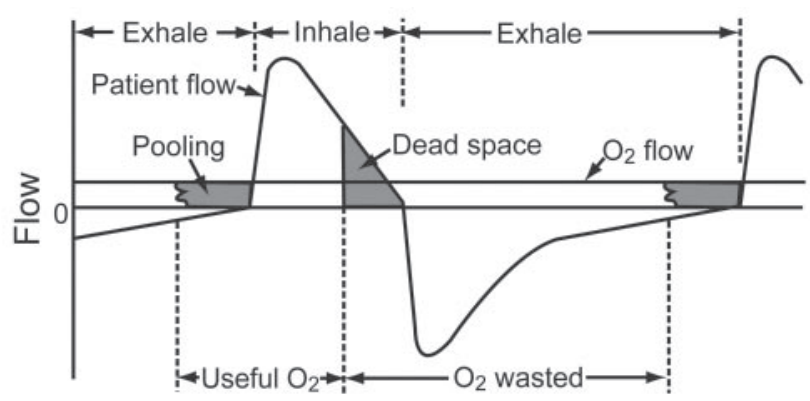

Fig. 1. Diagram of a respiratory flow cycle in relationship to continuous-flow supplemental oxygen, indicating the sections of the breathing pattern that useful oxygen is delivered.

Some evidence exists on the clinical capabilities and benefits of several new LTOT devices, yet they are tested on a limited number of patients, and are products with only specific applications. ${ }^{4}$ The focus of providing home oxygen equipment appears to be on the availability of an oxygen system and the process of delivery and set-up of that system in the patient's home. Little comparative research has described the variability of home oxygen products $^{5}$ related to the patient's disease requirements with an overall goal of ensuring adequate patient oxygenation at all activity levels. Much of the evidence-based research for LTOT does not indicate what device was selected for patient use, including a description of the oxygen equipment's capabilities and limitations. These variables could impact the consistent delivery of oxygen and the effectiveness of therapy.

Patient monitoring at frequent intervals is another limiting factor related to ensuring the clinical benefits of LTOT, again, creating an uncertainty on whether the patient is oxygenating on a specific system at all activity levels throughout their course of therapy. The literature for LTOT generally indicates that patients were placed on oxygen at a set or equivalent flow rate, with the assumption that the patient was oxygenating at all activity levels. If oxygen is a controller medication, as indicated by Dunne, ${ }^{3}$ more emphasis should be placed on the assessment, prescription, and monitoring of LTOT, to gain the maximum benefits from oxygen products and services. This review will describe the many options available for LTOT equipment and the variability in capability and performance, suggesting that, when using home oxygen equipment, clinical 
intervention is critical to gaining patient benefits and to reducing complications and comorbidities.

\section{Evolution of Home Oxygen Equipment}

Initially, pressurized cylinders were the available options for oxygen therapy in the home, using the same equipment utilized in the hospital. Cylinder capabilities and applications were familiar to hospital-based clinicians, so understanding of performance capabilities was not an issue when prescribing and initiating home-based LTOT. In 1965, the first home based liquid oxygen (LOX) system was developed to provide both a stationary and portable oxygen system for patient use within the home. ${ }^{6}$ The main advantages of this system were the ability to refill the portable LOX system when needed, with the system weight and operating time efficiency that surpassed the capabilities of compressed gas cylinders. Patients could fill their portable system whenever needed and have the advantage of a lighter weight system capable of extended use before refilling. Many clinicians were not familiar with the mechanics and operation of home LOX systems, yet these devices were essentially equivalent to the piped oxygen systems utilized within the hospital. Stationary oxygen concentrators became available in 1973, allowing for the generation of oxygen in the home by filtering nitrogen from the air. ${ }^{7}$ This provided an unlimited supply of oxygen to the patient, as long as electricity was available and the device operated within specifications.

Stationary concentrators produced a different purity of gas $(90 \% \pm 5 \%)$ than hospital oxygen. Providers of hospital grade oxygen have strict guidelines for the production and monitoring of oxygen, and are regulated at $99 \%$ purity. Many hospital-based clinicians assume the standard of oxygen purity would apply to home-based equipment. During the first oxygen consensus conference it was recommended that, for reimbursement purposes, concentrator oxygen was considered equivalent to $99 \%$ oxygen, allowing home oxygen providers to use concentrators without payment issues. ${ }^{8}$ Several studies have indicated that clinicians should consider oxygen purity when prescribing LTOT and take into consideration the device that will be used in the home when titrating a patient for therapeutic settings. ${ }^{9,10}$ Concentrator oxygen utilization began the trend away from the perception that home oxygen is the same as hospital oxygen, with oxygen production variability becoming a more important issue with concentrator miniaturization.

Now there are combinations of compressed gas, LOX, concentrator, concentrators that fill compressed gas, LOX portables, and battery operated concentrator systems available for home oxygen therapy. Each new home oxygen system has a different performance characteristic, with capabilities and applications that are unique to the product.
Clinicians need be aware of product variability in performance when prescribing and placing a home oxygen patient on a specific system. Home oxygen therapy equipment should not be considered a commodity for which any home oxygen product can be used, regardless of the therapeutic objectives for the individual patient.

\section{Home Oxygen: Equipment Economic Issues}

The key driver that has impacted the development of home oxygen equipment has been the economic pressures related to reimbursement for LTOT. ${ }^{11}$ Payers of home oxygen equipment have a different perspective related to reimbursement for LTOT, and have reduced reimbursement continually over the last 2 decades, focusing on the availability of oxygen equipment as opposed to effective patient oxygenation. Reimbursement for professional respiratory therapist (RT) services in the home is not available, further suggesting that equipment rather than patient oxygenation is the focus of the insurance industry. Equipment distribution costs and patients' need for equipment that meets their lifestyle requirements have further driven product design that addresses these issues, yet there has been no substantial research to determine patient applications, safety, or effectiveness. Several new clinically targeted oxygen products have been developed, yet have not gained traction, due to the lack of clinical evidence and adequate reimbursement. ${ }^{12,13}$ Clinical capabilities have not been a driving force from prescribing physicians, so costs and marketing advantages have been the main design considerations from oxygen equipment manufacturers. Oxygen equipment is the means to provide therapy and cannot be considered the end point related to the effectiveness of home oxygen therapy.

\section{Oxygen Equipment: From Hospital to Home}

Dr Thomas Petty was instrumental in raising the awareness of LTOT and the benefits this therapy can provide. ${ }^{14,15}$ Equipment provided an opportunity to supply LTOT, yet also added a variable to the therapy, with technology and a new therapy delivery environment in the home. The home is not the hospital, yet most testing and research have been conducted in a controlled institutional environment that does not represent the patient's home. Patients benefit from activity, and the need for oxygen during activity has stimulated the study of home oxygen therapy, which has led to new technologies. Pulmonary rehabilitation with LTOT determined that patients can exercise with chronic lung disease and that proper education and equipment can improve a patient's quality of life and reduce complications and mortality related to COPD. ${ }^{16}$ The Nocturnal Oxygen Therapy Trial was the foundational research on the benefits of LTOT, and a review of the Nocturnal 
Oxygen Therapy Trial demonstrated the economic benefits of ambulatory oxygen therapy on hospital admissions. ${ }^{17,18}$

\section{Home Oxygen: Drug or Device?}

Home oxygen equipment has evolved to address the challenges of providing oxygen therapy in the home environment with new and innovative technology and creative packaging that reduces costs and improves patient adherence. A concern for the therapeutic effectiveness of this new home oxygen technology stimulated research that demonstrated the variability of products in consistently oxygenating patients. ${ }^{19}$ Intermittent-flow devices introduced to the home in 1983 started the greatest departure from traditional continuous-flow oxygen delivery used in the hospital. ${ }^{20}$ Intermittent-flow devices addressed the need to improve efficiency of oxygen delivery by providing flows only when the patient was inhaling, eliminating the waste of gas during exhalation. This efficiency has been used with portable oxygen systems to reduce size and extend operating times, and has created ambulatory systems that are patient friendly, improving adherence. Intermittent-flow devices have also created the greatest confusion related to oxygen delivery, related to prescriptions, device selection, understanding patient versus product capabilities, and reimbursement for LTOT.

\section{Home Oxygen: A Mobility Solution}

Home oxygen patients need to be highly mobile to maintain a normal lifestyle. Ambulation has been shown to improve survival, reduce cost, and reduce complications associated with chronic lung disease. ${ }^{21}$ A portable oxygen system must be effective and efficient to gain patient adherence, yet must also provide therapeutic oxygen at all activity levels. A factor that has become the most daunting for home oxygen therapy is the third-party payer's willingness to pay for the necessary equipment. The current practice of payers is to continually reduce reimbursement for LTOT products, with the assumption that LTOT costs will diminish. The reality is that those patients who do not receive therapeutic oxygen allowing them to maintain mobility will increase overall cost by returning to the hospital with complications associated with under-oxygenation and a sedentary lifestyle. ${ }^{22}$

\section{Sources of Oxygen for Home Use}

Oxygen utilized in the home must be delivered or produced. Packaged gas is created by an industrial gas producer under strict guidelines for purity and packaging. Oxygen is monitored and tracked each time it is repackaged, with tracking systems in place to ensure the quality of the gas. The size of a packaged gas system determines its application and operation times between refills. There are many options available for both stationary and portable package gas systems for home oxygen utilization.

\section{Oxygen Produced, Stored, and Transported by a Gas Manufacturer and Home Medical Equipment Supplier}

- Compressed gas (fractional distillation) 99\% United States Pharmacopeia oxygen

- LOX (fractional distillation/refrigeration) 99\% United States Pharmacopeia oxygen

- The fractional distillation process is highly regulated by the gas industry for oxygen purity, with precision monitoring and documentation.

\section{Oxygen Produced Within the Home by Oxygen Concentrator}

- Concentrator oxygen (pressure swing adsorption) $90 \pm 5 \%$ purity

There is little regulation on gas production purity for pressure swing adsorption products, with no monitoring requirements other than manufacturer recommendations.

Oxygen produced in the home is typically accomplished with devices that filter nitrogen from ambient air. Stationary concentrators are well established, with a history of reliability and performance. Portable oxygen concentrators (POCs) are newer, with performance and capabilities that are not as well established as the larger stationary systems. Oxygen purity levels for concentrators are generally considered to be between $85 \%$ and $95 \%$ fraction of delivered oxygen $\left(\mathrm{F}_{\mathrm{DO}_{2}}\right)$, and some systems (yet not all) have oxygen monitoring capabilities. Oxygen monitoring of home oxygen concentrators is not required by regulatory agencies or, more importantly, prescribing clinicians. Repackaging of concentrator gas in the home to a cylinder or LOX system is not regulated, and each manufacturer can determine what monitoring they will provide. Devices that fill from a home oxygen concentrator have a proprietary coupling system to ensure that other portable oxygen systems cannot be filled from the designated stationary system. $\mathrm{F}_{\mathrm{DO}_{2}}$ within the portable system will be the same as the $\mathrm{F}_{\mathrm{DO}_{2}}$ from the stationary source gas.

Compressed gas systems have a finite capacity, depending on the size and pressurization of the cylinder. These systems require a refill process with an associated service and cost that factor into the delivery and portable application. LOX systems are both stationary and portable and require a refill process, yet the portable can be filled from the stationary, allowing the patient control of the frequency of refilling the portable. LOX stationary systems are refilled at a set frequency, depending on the size of the unit and flow setting, again with a service cost. Oxygen con- 
centrators create oxygen in the home, so do not require refilling, yet the power source (alternating current or battery) becomes the determining factor for availability of therapeutic oxygen and operating times. Stationary concentrators can produce up to $10 \mathrm{~L} / \mathrm{min}$ of $90 \%$ oxygen, and portable concentrators range from $0.4 \mathrm{~L} / \mathrm{min}$ to $3 \mathrm{~L} / \mathrm{min}$ production. Production capacity determines flow and dose capabilities for oxygen concentrators used within the home.

\section{Metering Oxygen to the Patient}

Historically, continuous flow has been the standard of care in all oxygen therapy environments. With the challenges of providing effective yet low cost oxygen therapy in the home, efficiency of gas utilization became a desirable objective. Metering of home oxygen to the patient evolved from continuous-flow therapy, with the introduction in 1983 of intermittent-flow delivery options. Over time, intermittent-flow delivery systems have increased the number of variables that need to be considered when providing supplemental oxygen.

Metering of home oxygen began with continuous-flow therapy, which was the standard in hospitals and considered the gold standard for LTOT. Continuous-flow therapy is simple to administer, and the equipment necessary for application is typically not complicated to operate, making it ideal for set-up in the home. Most continuous flow products deliver flows ranging from $0.5 \mathrm{~L} / \mathrm{min}$ to $5-6 \mathrm{~L} / \mathrm{min}$, with some products able to deliver up to $15 \mathrm{~L} / \mathrm{min}$. Changes in flow setting are made simply by turning a dial or pressing a button. Patients using effective continuous-flow therapy are generally able to "set it and forget it." By nature of the application, continuous-flow therapy has a variable dose that changes with breathing frequency and other physiological factors, yet even with the minute volume limitations of continuous flow, its application is familiar to clinicians and still readily accessible within most healthcare institutions.

\section{Estimate of Continuous Flow $\mathrm{F}_{\mathrm{IO}_{2}}$ From a Nasal Cannula}

Cannula flow $2 \mathrm{~L} / \mathrm{min}(33 \mathrm{~mL} / \mathrm{s})$

Tidal volume $500 \mathrm{~mL}$

Anatomic reservoir $50 \mathrm{~mL}$ (nasal passages and nasopharynx)

Inspiratory time 1 second

Volume of $\mathrm{O}_{2}$ inspired

$50 \mathrm{~mL}+33 \mathrm{~mL}+84 \mathrm{~mL}$ (amount of $\mathrm{O}_{2}$ in the inspired air $=420 \mathrm{~mL} \times 0.21)$

Volume of inspired oxygen $=167 \mathrm{~mL}$

$\mathrm{F}_{\mathrm{IO}_{2}}=167 \mathrm{~mL}\left(\mathrm{O}_{2}\right) / 500 \mathrm{~mL}$ (tidal volume) $=0.33 \mathrm{~F}_{\mathrm{IO}_{2}}$

The goal of oxygen therapy is to provide the necessary amount of therapeutic oxygen to gas exchange units as efficiently as possible to maintain oxygenation at all activity levels. ${ }^{23}$ Useful oxygen delivery occurs during a specific time frame within the breathing cycle. ${ }^{24}$ This "sweet spot" is where the benefit of oxygen delivered to gas exchange units within the lung is maximized. Providing oxygen anywhere outside this effective gas exchange areasuch as during exhalation-is considered wasteful. Even oxygen delivered during inhalation can be wasteful: gas that remains in dead space before being exhaled is not useful gas. The solution to eliminating wasteful oxygen was by utilizing intermittent-flow delivery. Intermittentflow delivery is as described: delivering oxygen in short bursts by repeatedly alternating the delivery setting from off to on. The awareness of intermittent-flow oxygen delivery technology existed prior to the introduction of a commercially available product, yet was rarely used. ${ }^{25}$ Practical application of intermittent flow was achieved in the early 1980 s.

Intermittent flow products have been labeled pulse-dose, demand flow, demand oxygen delivery systems, and/or oxygen conserving devices. Intermittent-flow devices require a metering method that senses, distributes, and ends dose delivery. These methods have included:

- Manually triggered/cycled: method identified in early research of the intermittent flow concept

- Pressure triggered/cycled: devices trigger on negative change in pressure (inhalation), cycle based on positive change in pressure (exhalation). These devices typically require a dual lumen cannula.

- Volume controlled: devices trigger on negative change in pressure (inhalation), and automatically cycle after delivering a set volume from a chamber within the device.

- Time cycled: devices trigger on negative change in pressure (inhalation), and electronically control the cycle time. These devices require a power source.

Control of the dose setting by a patient on an intermittent-flow device has expanded from the traditional manual dialing to novel methods of changing the dose setting based on patient needs. These methods have included:

- Manual adjustment of the intermittent flow device by the clinician or patient

- Motion control: the intermittent-flow device senses movement, and, assuming the patient's demands for oxygen increase with activity, increases the dose volume. The device returns to baseline when motion is not detected.

- Respiratory rate control: the intermittent-flow device adjusts the dose setting based on breathing frequency. Currently there is only one device that meters the dose volume based on rate. ${ }^{26}$ 
- Oximeter control: the intermittent-flow device monitors the patient's oxygen saturation and meters the dose of oxygen based on a targeted oxygen saturation level. ${ }^{12,13}$ This type of intermittent-flow device has been described in the literature, yet no commercially available product has been introduced to the United States market.

Initially, intermittent-flow devices were described as equivalent to continuous-flow as a means to gain approval from the federal government for a product's release. These products were usually labeled similar to continuous-flow devices, with numerical settings from 0.5 up to 5 or 6 . Once on the market, intermittent flow products often included marketing material describing the device's settings as equivalent to continuous-flow delivery (eg, a setting of "3" was equivalent to $3 \mathrm{~L} / \mathrm{min}$ continuous flow). However, delivering oxygen intermittently should not be considered the same as delivering oxygen continuously. Equivalence of intermittent-flow delivery to continuous-flow delivery is dependent on a number of variables, yet when one or more of these variables change, the equivalence of an intermittent-flow delivery method to continuous-flow delivery cannot be achieved. In early application of intermittent-flow therapy, this concept was not well understood, and had many people perceiving that intermittent flow and continuous flow, set to an equivalent setting number, were the same.

This first misunderstanding lead to a perception that intermittent-flow devices did not work. Manufacturers who had labeled their devices as equivalent to continuous-flow were also able to market the "oxygen savings ratio" that resulted from the use of their product by comparing the volume of oxygen delivered during continuous flow to the volume their device delivered at an "equivalent" intermittent flow setting. These oxygen saving ratio values lead to marketing claims that one device was better at conserving oxygen, and became an important factor in the selling of oxygen conserving devices. Because of the lack of information available during early use of intermittent-flow delivery systems, instead of considering that there may be another intermittent-flow device that would meet the patient's needs, many clinicians assumed that all intermittent-flow devices would not work.

Shigeoka described the then (and remarkably current today) state of oxygen conserving devices in a 1985 editorial $^{27}$ by describing the variability of continuous-flow volume delivery at different breathing frequencies and noting how conserving devices might overcome some of the continuous flow limitations. Also identified in that editorial was the fact that very limited studies were available comparing intermittent flow to continuous flow, and those that were available were conducted under laboratory conditions and/or generally conducted in ideal conditions by the inventor or manufacturer. ${ }^{27}$ Studies during sleep, ex- ercise, or in children had not been reported, and only limited information is still available today.

Early recommendations for prescribing LTOT suggested increasing a continuous-flow setting by $1 \mathrm{~L} / \mathrm{min}$ with exercise and/or sleep to maintain adequate oxygenation during these activities. Interestingly, most evidence for the effectiveness of intermittent-flow LTOT does not take into consideration many of the variables that are introduced with intermittent-flow delivery, and often assume a consistent $\mathrm{F}_{\mathrm{IO}_{2}}$ throughout the investigations. Research demonstrating the value of LTOT in different applications (at rest, and at activity) often does not indicate how the oxygen therapy was monitored, if the metered flow of oxygen was adjusted in response to changing breathing frequencies, and/or what system was used for the delivery of oxygen. Many researchers appear to simply assume that the oxygen delivery was consistent during their study. Much of the literature generally describes oxygen therapy as "oxygen was given." Many of these studies ignore specific details necessary to understand how the oxygen was metered and delivered, meaning that the $\mathrm{F}_{\mathrm{IO}_{2}}$ could have varied considerably and may have affected the findings and conclusions.

Delivering some oxygen is better than giving no oxygen, ${ }^{28}$ yet providing oxygen as a therapeutic drug in a multitude of ways may change effectiveness and patient outcomes. Intermittent-flow delivery, as described by Pflug, ${ }^{29}$ introduced a more efficient method of oxygen delivery by eliminating wasteful oxygen flow. Intermittent-flow delivery has the ability to provide a specific dose of oxygen that can be measured and controlled to provide consistent therapy. However, since their inception, intermittent-flow devices have often claimed equivalency with continuous-flow, which has led to confusion on the effectiveness of these devices. ${ }^{30}$ It is important to understand that equivalency to continuous flow is possible based on certain variables, like volume and breathing frequency, yet a standard for metering and labeling of intermittent-flow devices has not been established, so any number on an intermittent-flow device should not be considered equivalent to continuous flow over a range of breathing frequencies. Even so, there is reason to believe that continuous 24 hour per day oxygen use, via intermittent-flow or continuous-flow methods, in appropriately selected patients could produce a survival benefit even greater than that shown in the Nocturnal Oxygen Therapy Trial. ${ }^{31}$

\section{Equipment Options}

Home oxygen equipment options have increased over the past decades, to the point where it is difficult to know what equipment is available and the capabilities and limitations of each device. Physicians typically prescribe a flow rate and frequency for home oxygen therapy and 


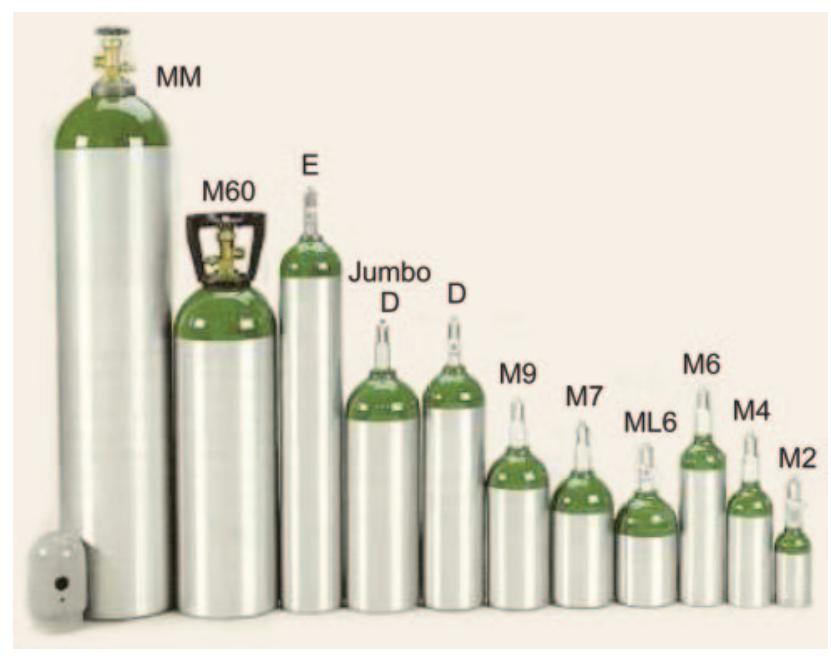

Fig. 2. Family of products showing the variety of sizes of compressed gas cylinders used in home oxygen therapy. (With permission.)

expect the HME provider to supply the necessary equipment. This lack of involvement has relinquished control of the oxygen therapy equipment delivery to the HME supplier. The HME will balance the decision of type of equipment used for the patient on their available inventory, distribution economics, competition within their market, and patient demands. Effective oxygenation at all activity levels is not a driving factor for the HME supplier, as reimbursement is not tied to documentation of oxygenation at all activity levels. Equipment provides the options for gas storage and metering within the home; however, clinicians need to ensure that the equipment is used therapeutically to gain patient benefits.

\section{Compressed Oxygen Cylinders}

Oxygen cylinders were the source of oxygen for hospitals until the advent of piped oxygen systems, which supplied large volumes of gas from bulk oxygen stored in cryogenic dewars. Oxygen cylinders are still the main source of portable oxygen within the hospital for patient transports. Patients in the home require the lightest cylinder that can operate for the longest period of time, to allow the patient to do activities of daily living. The balance between weight and operating times was the impetus to deliver oxygen to the patient more efficiently. Aluminum cylinders replaced steel cylinders for home use, to reduce weight (Fig. 2). Aluminum regulators further reduced weight, and novel carts and carrying devices added to the patient ease of use of cylinder gas. Composite cylinders are available that reduce weight and have the potential to be filled to higher pressures, up to 3,000 psig. Even though the potential for increased pressure operation is available, many industrial trans-filling services do not operate at over

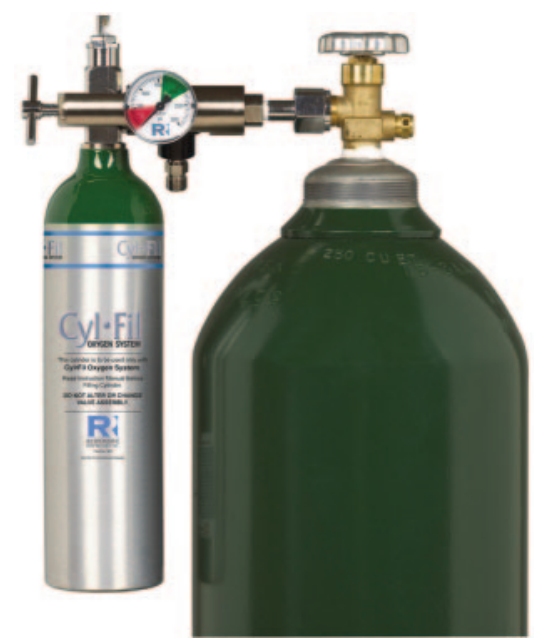

Fig. 3. Cyl-Fil compressed oxygen trans-filling system, using large cylinders to fill smaller cylinders. (Courtesy of Responsive Respiratory.)

$2,000 \mathrm{psig}$, due to the need to modify equipment to fill to $3,000 \mathrm{psig}$.

Large cylinders can trans-fill smaller cylinders in the home, as an option to reduce the cost of newer equipment and utilize readily available compressed gas systems (Fig. 3). This old concept became available again due to the constant economic pressures from payers to reduce reimbursement for home oxygen equipment

\section{Liquid Oxygen Systems}

LOX provides several advantages over cylinders. Oxygen in a liquid state can be stored, transported, and transfilled more efficiently than gas systems (Fig. 4). With an 860:1 expansion ratio, $1 \mathrm{~L}$ of LOX will expand to $860 \mathrm{~L}$ of gaseous oxygen. This efficiency is utilized in the hospital with large cryogenic storage dewars supplying oxygen in large volume. In the home, stationary dewars come in a variety of sizes, with the option of determining delivery cycles based on the size of the stationary dewar. Portable LOX systems can be trans-filled in the home from the base dewar, which allows for a quick refill of the portable, with the further advantage of the need for only one portable LOX system. Small stationary dewars have been used when patients want to have a refill supply available in the car or van during extended trips from their house (Fig. 5).

High-flow LOX can provide up to $15 \mathrm{~L} / \mathrm{min}$ of continuous flow oxygen at a purity of $99 \%$. High-flow LOX has an operational issue with the potential to create ice on the portable due to ambient humidity freezing on the heat exchange coils. Patients utilizing high-flow LOX usually have 2 systems available, to allow one unit to de-ice while 


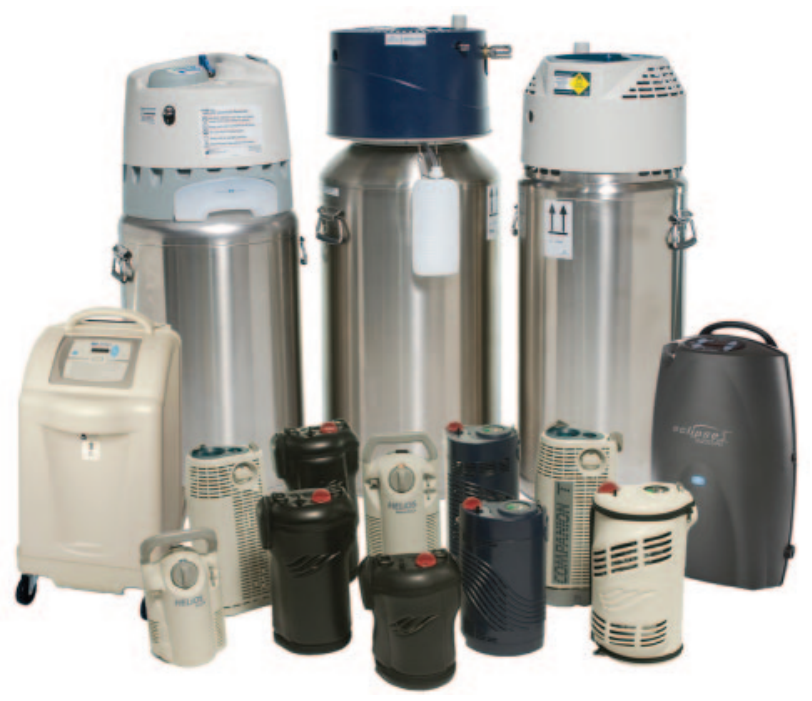

Fig. 4. Family of products showing the many options for both stationary and portable liquid-oxygen home oxygen systems. (Courtesy of Caire Medical.)

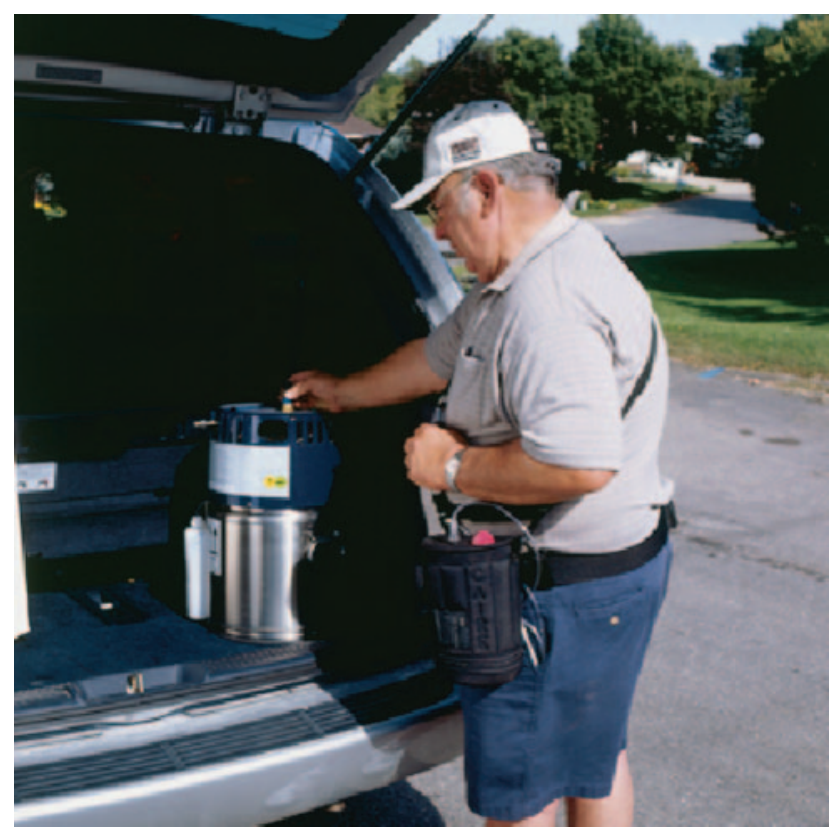

Fig. 5. A patient trans-filling a portable liquid-oxygen container from a small stationary system secured in the back of a car. (Courtesy of Valley Inspired Products.)

the other unit is in use. LOX is the most practical option for patients requiring ambulatory high-flow oxygen.

LOX production in the home is now possible with the introduction of a commercially available product (Fig. 6). The home liquefier uses concentrator gas that is cooled to cryogenic temperatures and stored in a dewar until needed. The unit produces $3 \mathrm{~L}$ of LOX and has a proprietary connector that allows the filling of only a dedicated portable LOX system. This system allows for the benefits of a LOX

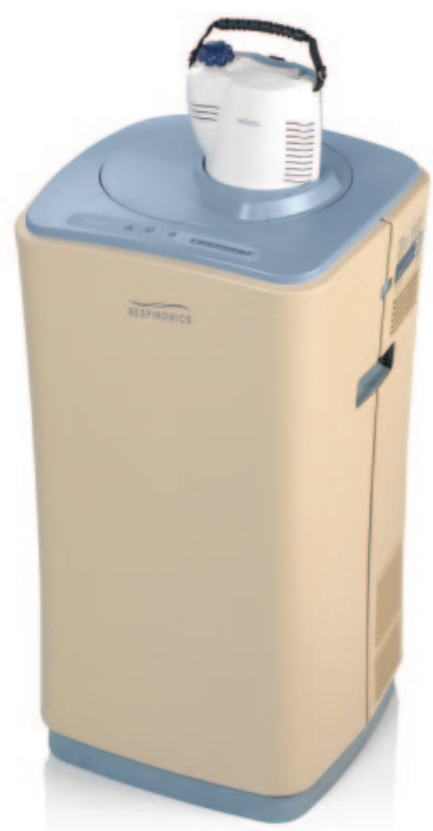

Fig. 6. HomeLOX liquid oxygen system, which creates oxygen from a concentrator and refrigerates the concentrator gas to a liquid state, which is stored in a small dewar to trans-fill to a liquid-oxygen portable. (Courtesy of Philips Respironics.)

portable without the costs of delivery from a home oxygen supplier. Acquisition costs, metering gas to the patient, and the cost of electricity to the patient are still a consideration in the acceptance of this product.

\section{Oxygen Concentrators}

Stationary concentrators provide a convenient and reliable source of oxygen in the home, with minimal limiting factors, the only major consideration being the availability of electricity and the capabilities of the device. Oxygen concentrators for home use are well established and the standard of care for stationary use. These units have the ability to produce $90 \% \pm 5 \%$ oxygen purity at flows ranges of 1-10 L/min (Fig. 7). The weight of current commercially available products is approximately 35 pounds, down from the initial weight in the mid 1970s of approximately 80 pounds. Benefits of today's units are lower power consumption, lower noise level, improved reliability, and reduced maintenance costs. These units are used within the home and can accept up to 100 feet of supply tubing to the patient, to allow for mobility within the home.

A $10 \mathrm{~L} / \mathrm{min}$ concentrator can address the needs of a higher flow patient with the same benefits of a $5 \mathrm{~L} / \mathrm{min}$ model, with only slight increase in size, weight, and electrical cost to operate. Oxygen concentrators that can fill cylinders have been developed to address the cost of resupplying portable oxygen cylinders for patient ambula- 

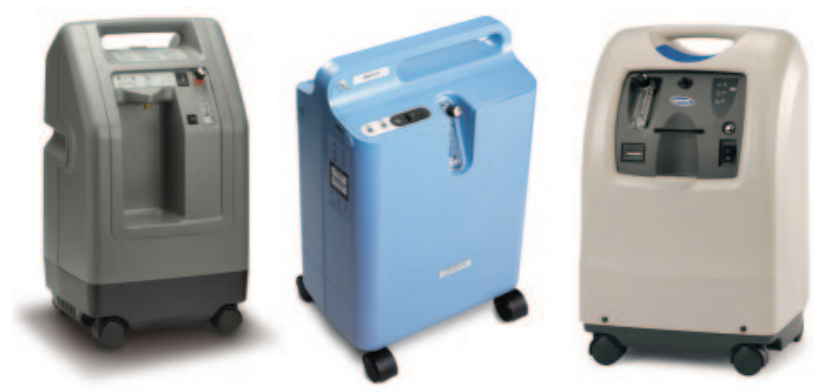

Fig. 7. A variety of stationary oxygen concentrators, with a flow range of 1-5 L/min. Left: 525 DS. (Courtesy of DeVilbiss Healthcare.) Middle: EverFlow Q. (Courtesy of Philips Respironics.) Right: Perfecto2. (Courtesy of Invacare.)
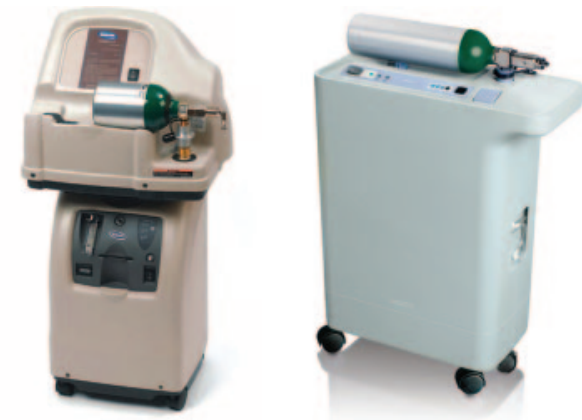

Fig. 8. Two stationary oxygen concentrator systems that can pressurize and fill compressed gas portable cylinders. Left: HomeFill. (Courtesy of Invacare.) Right: UltraFill. (Courtesy of Philips Respironics.)

tion (Fig. 8). Patients are able to refill their portable cylinders by mating the portable to the stationary unit, utilizing a proprietary connection. These devices can pressurize cylinders to 2,000 psig ( 2 commercially available units), and one manufacturer has a product that can pressurize a composite cylinder to 3,000 psig. Patients should be provided an adequate number of refill cylinders to allow for the extended refill times of the portable and for extended operating times away from home. Patient issues with the home trans-filling concentrators are the availability of extra cylinders, fill times of the cylinders, and a slight increase in electrical costs. The choice of the appropriate regulator to meter oxygen to a therapeutically effective level is also a consideration for these devices.

\section{Intermittent-Flow Regulators}

Intermittent-flow regulators, either stand-alone or as an integrated part of an oxygen system, deliver a volume of oxygen during inhalation, with no oxygen delivery during exhalation (Fig. 9). Unlike continuous-flow therapy, as the patient's breathing frequency increases, intermittent-flow delivery systems have the capability to deliver the same

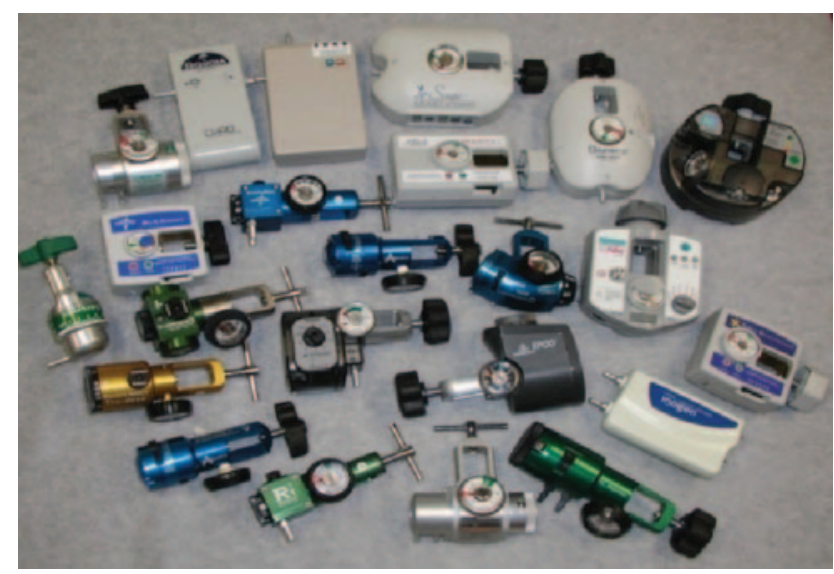

Fig. 9. A variety of compressed gas oxygen regulators that provide intermittent flow. (Courtesy of Valley Inspired Products.)

volume of oxygen per breath, no matter the breath rate. ${ }^{32}$ Some intermittent-flow devices do mimic continuous-flow delivery using a minute volume delivery method that decreases the dose volume as the breathing frequencies rise, often with secondary outcomes of ensuring that the device does not exceed production capabilities or prolonging oxygen conservation. But for fixed-dose intermittent-flow devices, in comparison to continuous flow, as breathing frequencies increase, more oxygen can be delivered to the patient per minute than at an "equivalent" continuous-flow setting. A patient using $2 \mathrm{~L} / \mathrm{min}$ continuous flow of $100 \%$ $\mathrm{O}_{2}$ with a $500 \mathrm{~mL}$ tidal volume breathing at 15 breaths/ min and a 1:2 inspiratory-expiratory ratio will receive $44 \mathrm{~mL}$ of $\mathrm{O}_{2}$ per breath; increase the rate to 30 breaths $/ \mathrm{min}$ with all other parameters the same and that delivered $\mathrm{O}_{2}$ volume drops to $22 \mathrm{~mL}$ per breath and $\mathrm{F}_{\mathrm{IO}_{2}}$ is reduced. But on an intermittent-flow device that delivers a fixed pulse of $44 \mathrm{~mL}$ per breath, the delivered volume does not change, and in theory the $\mathrm{F}_{\mathrm{IO}_{2}}$ would stay the same.

There are several factors that determine just how much of a delivered volume from an intermittent-flow device-in both fixed-dose and minute volume delivery scenariosactually reaches the lungs (Fig. 10). Intermittent-flow devices need some mechanism to turn on and turn off oxygen delivery, and to meter the dose when delivery is occurring. The ability of these devices to "trigger" is variable by product, and delivering earlier or later in the inhalation cycle can affect how much volume reaches gas exchange units in the lungs. If the intermittent-flow device is sourced by a concentrator or other supply with $<100 \%$ oxygen, the $\mathrm{F}_{\mathrm{DO}_{2}}$ of the delivered oxygen will play a role in the $\mathrm{F}_{\mathrm{IO}_{2}}$ of the patient. The shape of the oxygen flow curve as the dose is delivered may also impact patient comfort and adherence. Down sides to higher flow and sudden on/off oxygen delivery, at least to a patient, are the sound that is produced by the device and within the cannula during 


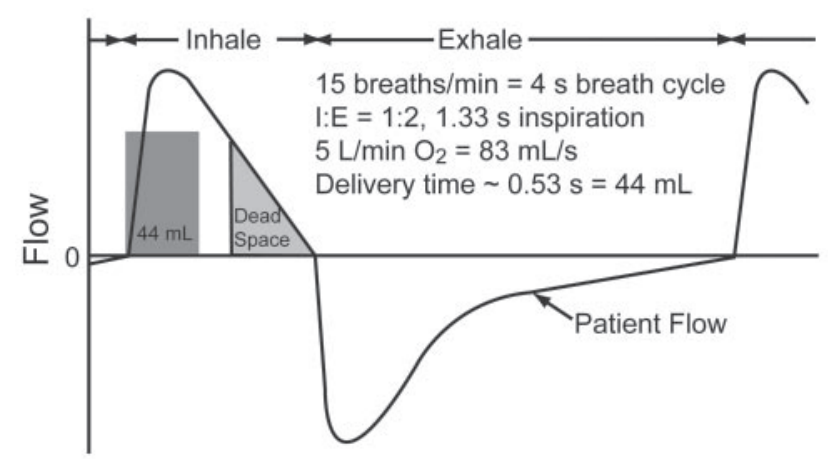

Fig. 10. A sample of how a volume of oxygen is calculated when determining an intermittent flow dose. This is a hypothetical sample and does not reflect a specific device.

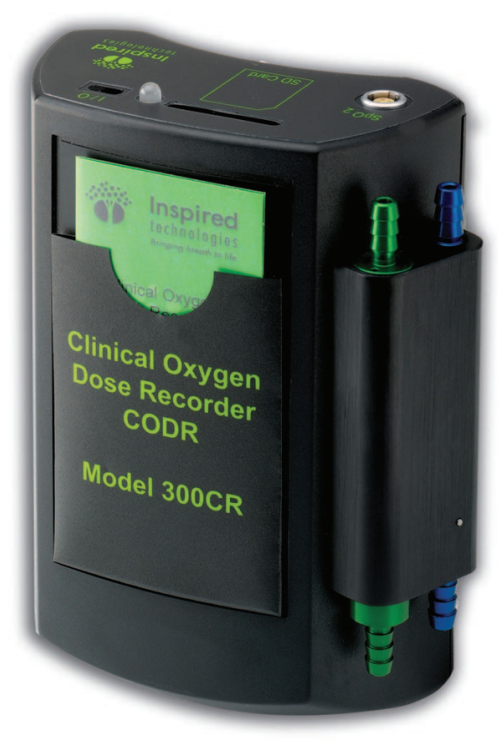

Fig. 11. Clinical Oxygen Dose Recorder device to monitor both the oxygen device and the patient. (Courtesy of Global Medical Holdings.)

delivery, and potential discomfort in the nasal cavity due to high flow.

\section{Oxygen Monitoring}

A new device has been introduced that can monitor both the oxygen delivery system and the patient (Fig. 11). This device connects between any oxygen system the patient would be using and has an oximeter to monitor the patient's oxygen saturation. The unit can transmit data wirelessly to a computer for monitoring and analysis or can store data for extended periods of time for trending analysis. This device provides the clinician with an objective tool for determining the appropriate oxygen device for the patient's needs at activity plus a method of electronically

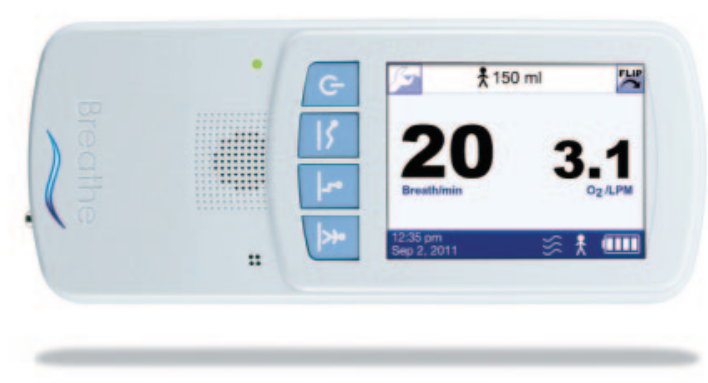

Fig. 12. Noninvasive Open Ventilation (NIOV) device that provides pressurized oxygen to augment ventilation. (Courtesy of Breathe Technologies.)

storing valuable information about the patient's oxygen use and benefit.

\section{Pressurized Oxygen}

Pressurized ambulatory oxygen to provide augmented ventilation has recently been introduced to address patient needs for assisted ventilation while receiving oxygen (Fig. 12). This device uses a nasal interface similar to interfaces used with CPAP and delivers a set volume of gas under pressure. This pressurized oxygen will augment ventilation to reduce work of breathing and improve a patient's capability to increase activities. The system weighs 1 pound and operates at $50 \mathrm{psig}$. Standard cylinders are utilized, allowing existing HME suppliers' inventory to be utilized. If assisted ventilation is necessary for a patient to benefit from LTOT, this product is now an option for consideration.

\section{Portable Oxygen Concentrators}

All LTOT patients are limited by the availability of adequate amounts of oxygen while mobile. POCs can manufacture oxygen from both alternating and direct current sources, so the capability of manufacturing adequate amounts of oxygen and electric power sources are the determining factor for the use of POCs. They were first introduced in the mid 1990s, yet have recently become more available, with several manufacturers introducing a variety of product options (Fig. 13). Knowing the capabilities of the POC, the needs of the patients, and their activities while using the $\mathrm{POC}$ are important points of information for the clinician to consider when working with the patient to determine therapy options. POCs vary from traditional home oxygen products as well as between different POCs. ${ }^{33}$ Recommendations from the second LTOT consensus conference state "Clinical evaluation should include regular assessments of patients' adherence with prescribed therapy, potential complications, potential 


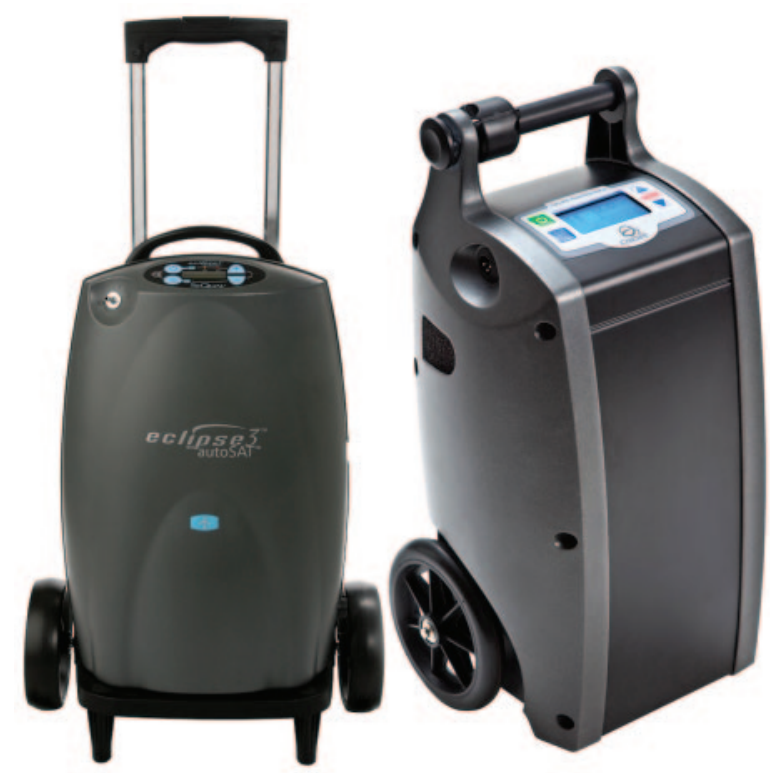

Fig. 13. Two options for $3 \mathrm{~L} / \mathrm{min}$ continuous-flow capable portable oxygen concentrator system. Left: Eclipse 3 (Courtesy of Caire Medical). Right: Oxlife Independence. (Courtesy of $\mathrm{O}_{2}$ Concepts.)

hazards, and the need for continued education. Patients receiving LTOT share responsibility with the prescribing physicians for remaining in communication with their physician, in order to assure continued appropriate care for their condition." 34

Each POC has different oxygen production capabilities and dosing algorithms that can impact patient oxygenation. These products are being marketed with features and benefits that are desirable to the LTOT patients, with weight, battery life, packaging, and sound being important consumer features. Once the patient has been tested, titrated, and ensured that the product they want keeps them properly oxygenated at all activity levels, the clinician should feel comfortable recommending a POC.

Larger POCs are available that can provide both $3 \mathrm{~L} /$ min continuous flow and a range of intermittent flow dosages. The larger production capabilities of these units give more options for higher-dose, intermittent-flow volumes. Continuous flow is available as an option for patients who do not consistently trigger the intermittentflow selection, or can be used if the patient requires a humidifier or to interface with other equipment such as a ventilator or CPAP.

Dr Petty suggested that "Practical portable concentrators should weigh no more than 10 pounds, produce $90 \%$ or more oxygen, and provide a least $2 \mathrm{~L}$ of oxygen for a minimum of 4 hours." This suggestion came at an American Association for Respiratory Care (AARC) Journal Conference in 2000.6 A product meeting these suggestions was introduced in January of 2012 (Fig. 14).

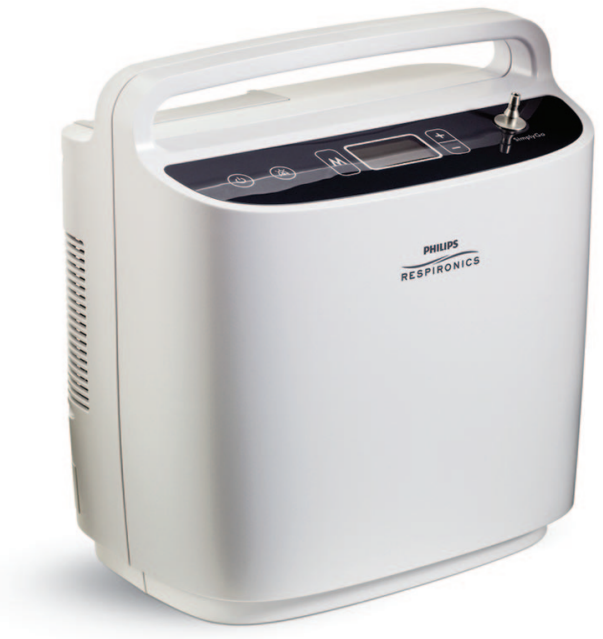

Fig. 14. SimpleGo, a $2 \mathrm{~L} / \mathrm{min}$ continuous-flow capable portable oxygen concentrator system. (Courtesy of Philips Respironics.)
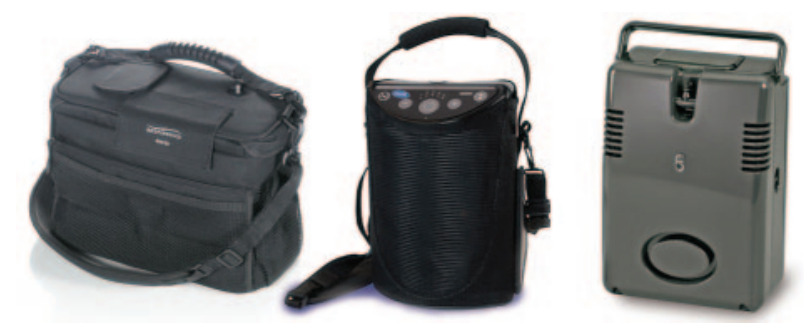

Fig. 15. A family picture of intermittent-flow-only portable oxygen concentrator systems. Left: EverGo. (Courtesy of Philips Respironics.) Middle: XPO2. (Courtesy of Invacare.) Right: FreeStyle. (Courtesy of Airsep.)

Intermittent-flow-only POCs produce a limited volume of oxygen that is not practical for continuous-flow operation (Fig. 15). The production capability of these systems is typically below $1 \mathrm{~L} / \mathrm{min}$. These devices provide intermittent-flow-only dosing with a volume per dose set by each manufacturer. The fixed production volume of these devices can be metered, with dose volume changing with breathing frequency changes, or can have a fixed dose of oxygen with oxygen purity reductions with higher breathing frequencies. With a fixed production of oxygen these devices cannot increase oxygen delivery beyond their production capabilities (Figs. 16-19).

The need for definitions of "portable," "ambulatory," and "wearable" was discussed at the 6th oxygen consensus conference, yet no agreement could be reached to categorize size, weight, and operating times for devices used away from their stationary oxygen device. ${ }^{35}$

New Issues Related to POCs. With the introduction of POCs, new performance variables have been introduced that can impact effective oxygen therapy. These variables, 


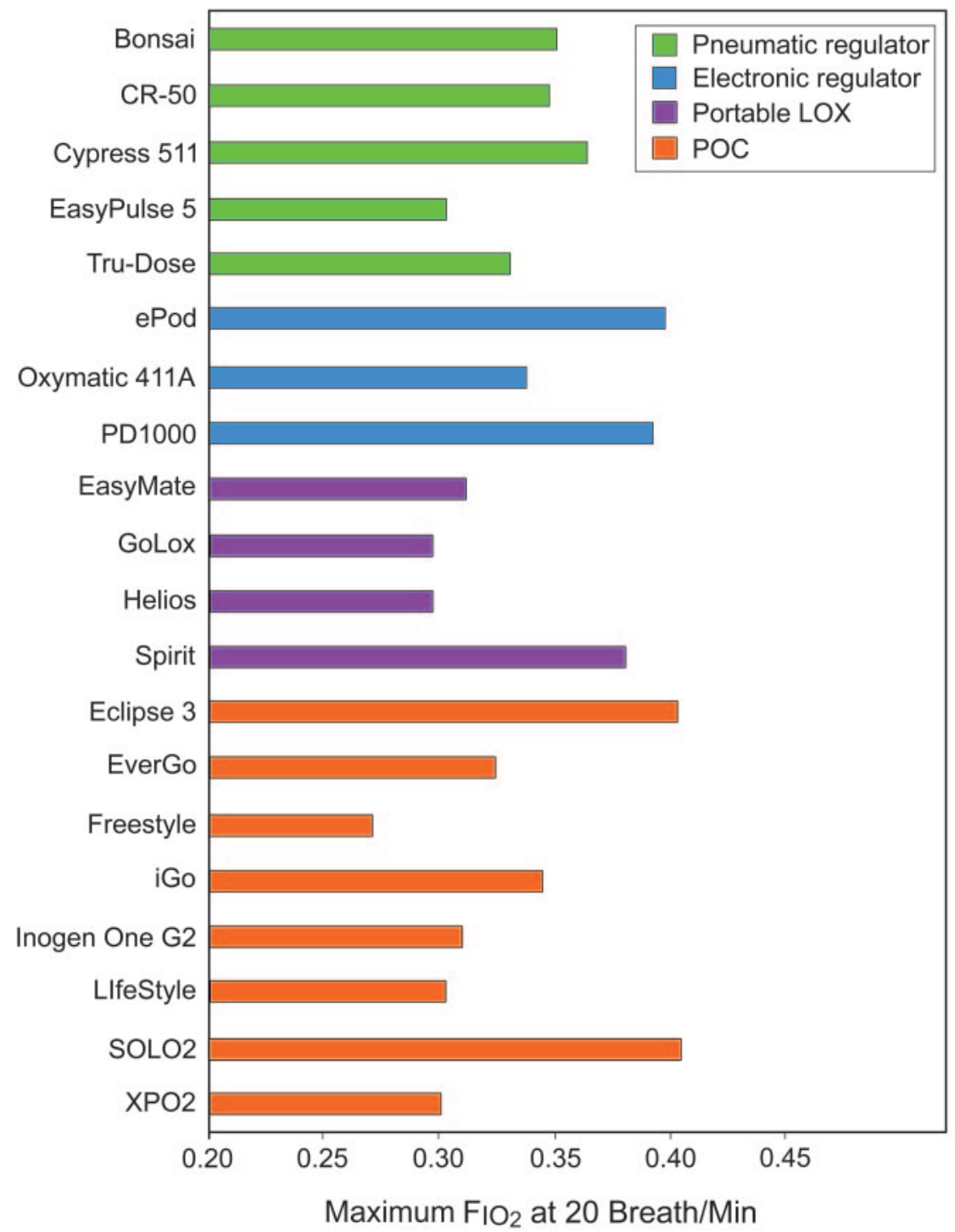

Fig. 16. The maximum $\mathrm{F}_{\mathrm{IO}_{2}}$ of a variety of portable oxygen systems, utilizing intermittent flow at 20 breaths/min. $\mathrm{LOX}=$ liquid oxygen. POC $=$ portable oxygen concentrator.

most not seen in continuous-flow therapy, require clinician, RT, and/or patient consideration when using a POC.

Stationary concentrators typically deliver oxygen continuously, at flow settings between 0.5 and $6 \mathrm{~L} / \mathrm{min}$ (with some units able to provide up to $10 \mathrm{~L} / \mathrm{min}$ ). Current POCs on the market, which are much smaller than stationary concentrators, do not have this range of capability. Some POCs are able to deliver up to $3 \mathrm{~L} / \mathrm{min}$ of continuous oxygen flow (continuous-flow POCs), but a majority of the POCs available are able to deliver their oxygen only intermittently (intermittent-flow POCs). The distinction between continuous-flow POCs and intermittent-flow POCs is important, if only because the oxygen production capabilities of these 2 types of POCs are different. Current continuous-flow POCs produce 2,000-3,000 mL of oxygen per minute. Oxygen production capabilities of currently available intermittent-flow POCs range from around $450 \mathrm{~mL} / \mathrm{min}$ up to $1,250 \mathrm{~mL} / \mathrm{min}$.

POCs have limited oxygen production capabilities and a maximum breath rate at which the device can maintain adequate $\mathrm{F}_{\mathrm{DO}_{2}}$. With an intermittent flow setting on a POC having a specific volume delivered, if a patient's breathing frequency-and thus the volume delivered per minuteexceeds the production capability of the POC, $\mathrm{F}_{\mathrm{DO}_{2}}$ will drop. Even POCs that feature minute volume delivery, where the dose delivered at a given setting decreases with an increase in breathing frequency, have a maximum breath rate and setting at which the device can deliver oxygen 
Options For Home OXYGEN THERAPy EQUIPMENT

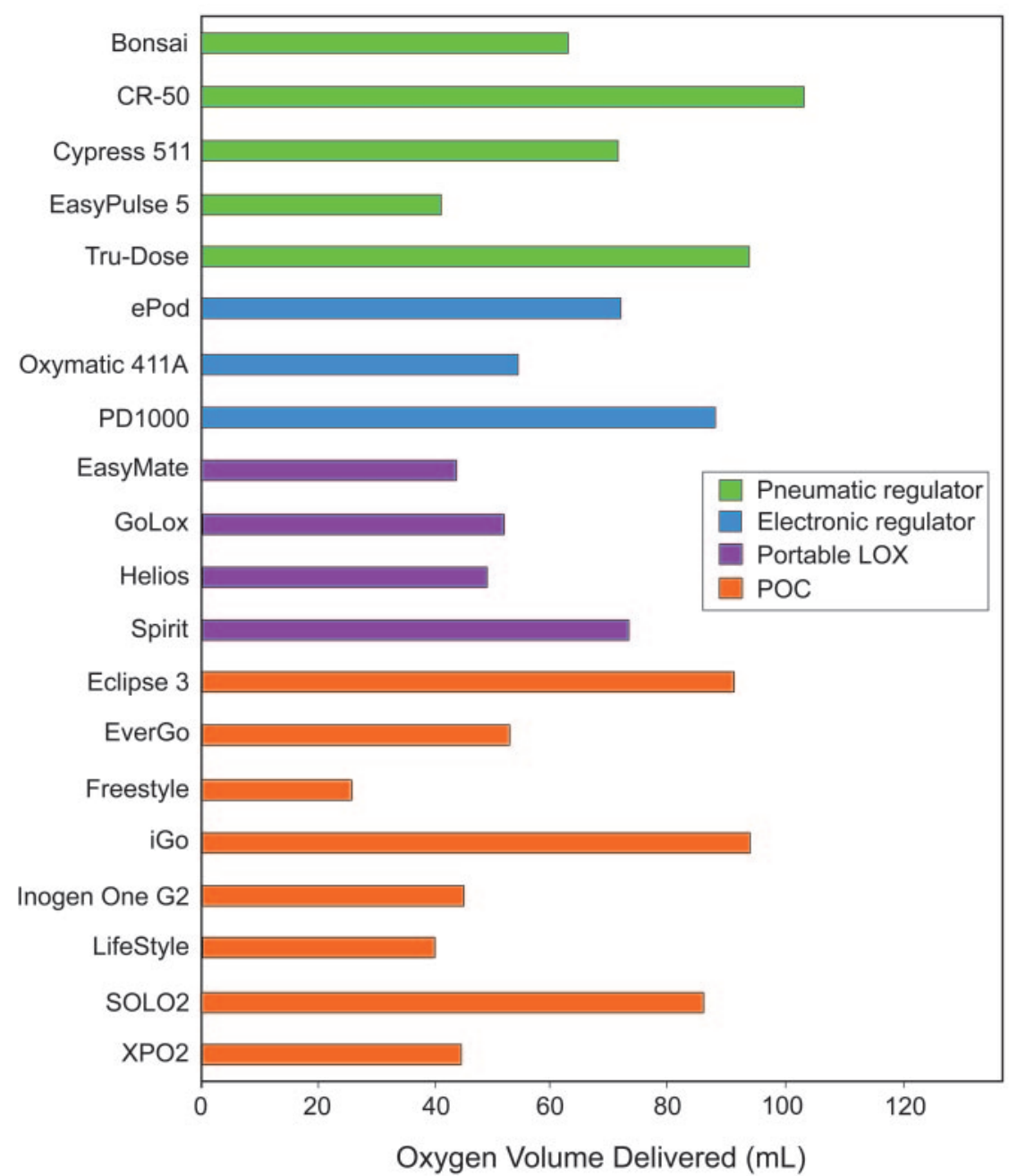

Fig. 17. The maximum oxygen dose of portable oxygen systems, utilizing intermittent flow at 20 breaths/min. LOX $=$ liquid oxygen. POC $=$ portable oxygen concentrator.

within specification. Often these maximum breath rates are not specified in the product literature.

Oxygen purity specifications from POC units usually range from $87 \%$ to $95 \%$. Many have $\mathrm{O}_{2}$ sensors that monitor oxygen purity or use internal pressure readings to indirectly gauge purity levels. However, each unit has different methods of alerting the user to low purity, and should purity levels fall below specification, some units may not display a visual indicator or audible alarm for several minutes. A reduction in $\mathrm{F}_{\mathrm{DO}_{2}}$ may affect patient oxygenation as a result of lower $\mathrm{F}_{\mathrm{IO}_{2}}$ being delivered.

Triggering sensitivity is a variable that can affect whether the device is able to detect inhalation and where in the inhalation cycle that the dose is delivered. Several POC manufacturers advertise that their products can be used while sleeping, even in intermittent-flow delivery only modes. Sleeping patients generally have slower breath rates and shallower breath patterns, meaning that any differences in triggering sensitivity ability across products are magnified. Cannula placement will affect triggering sensitivity, so if the patient inadvertently moves their cannula, the intermittent-flow device many not trigger or trigger later in the breathing cycle. Intermittent-flow-only POCs do not have the ability to switch to a continuous-flow mode should breathing remain undetected. Continuousflow POCs are able to switch to a continuous-flow mode in the absence of breath detection, but some continuousflow POCs will remain in continuous-flow mode, while others will cycle between intermittent flow and continuous flow until a breath is detected (which has an added benefit of conserving battery life).

When a wall or grounded power source is unavailable, the battery life of a POC becomes the determining factor for device operating times. Battery designs and longevity 

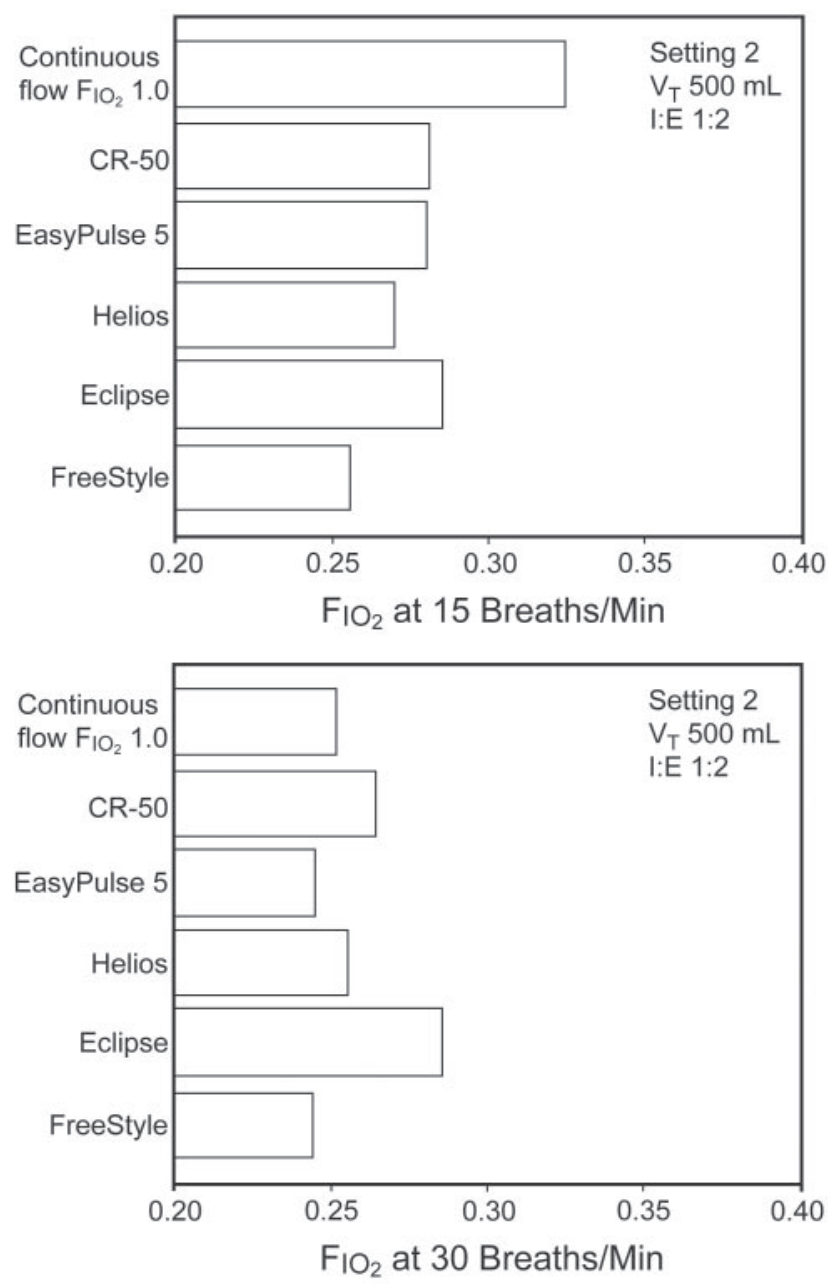

Fig. 18. The $\mathrm{F}_{\mathrm{IO}_{2}}$ of a variety of intermittent-flow devices at 15 and 30 breaths $/ \mathrm{min}$.

have improved, yet are still a consideration for a patient who needs to be away from a power source for a substantial period of time. Unlike packaged gas systems, where replenishment of depleted oxygen is dependent on delivery schedules and other factors outside of the patient's direct control, power availability is much greater with electrical sources readily available. A patient using a POC on battery is meant to bridge the time from one power source to another, and reduces the patient's fear of running out of oxygen.

Patient education on the operation and capabilities of POCs is necessary, as service from the oxygen provider is decreasing and more patients are purchasing home oxygen products like POCs on their own. Patients almost always want the lowest weight, longest lasting POC available, yet these products are not always able to meet their oxygenation needs. Advertising has enticed patients with claims of low weight, equivalency to continuous flow, 24/7 use, and long battery life. These are factors to consider, yet any
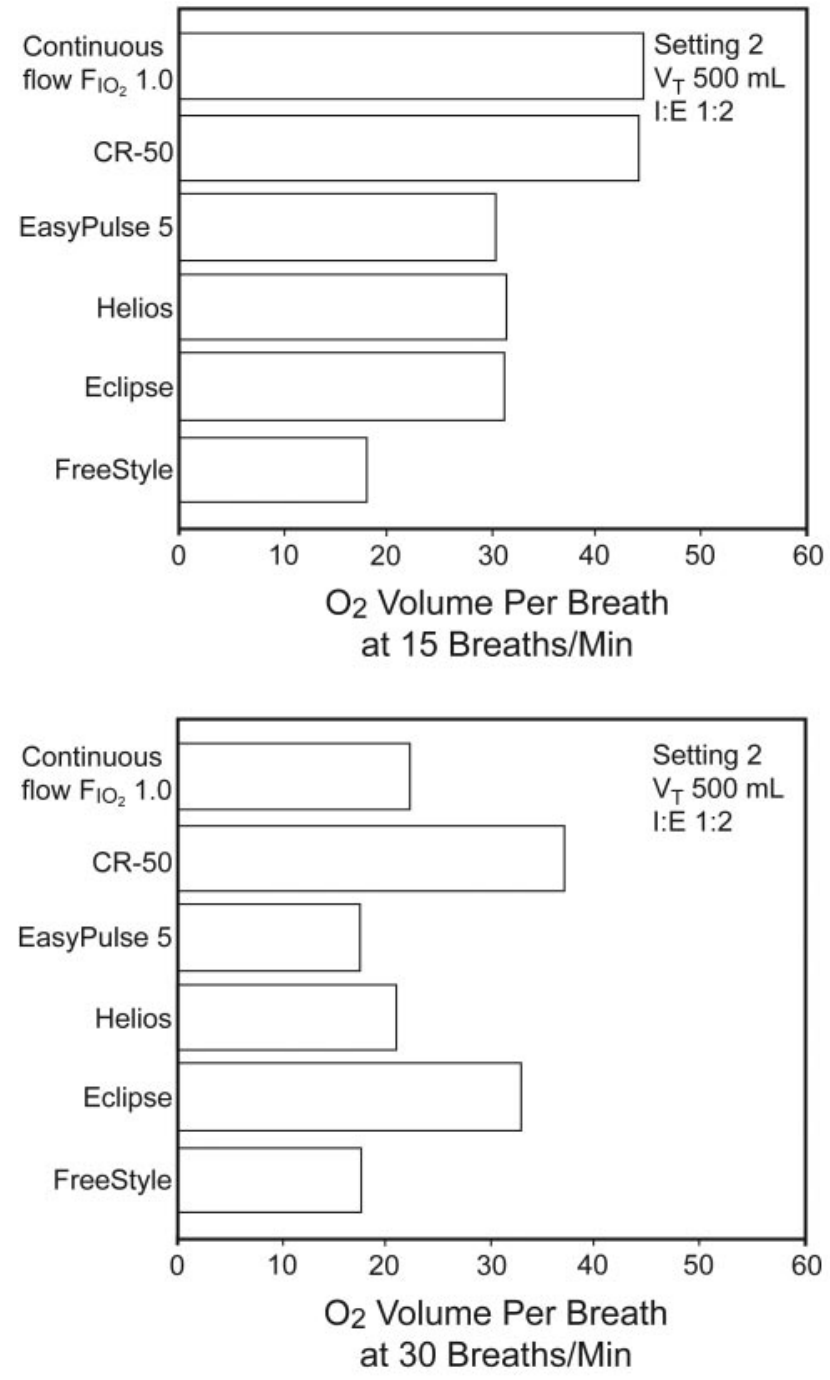

Fig. 19. The volume of gas provided per breathe from a variety of intermittent-flow devices at 15 and 30 breaths/min.

benefit from these product variables should be secondary to effective oxygenation at all activity levels.

\section{Discussion}

Oxygen has proven to be an effective drug in treating hypoxemia, with a broad range of applications both in the hospital and the home. Patients with diseases causing chronic hypoxemia require supplemental oxygen continuously to prevent consequences and comorbidities. Home oxygen equipment options expanded as patient and economic needs increased, without the direction of the physicians and research community regarding oxygen delivery capabilities, range of oxygen delivery, and oxygen purity of home oxygen devices. Early research on new oxygen products showed differences in performance and capabilities, but the influx of new products was too fast for a 
widespread understanding of their capabilities and outcomes to be achieved. Manufacturers and DMEs capitalized on the interest in intermittent-flow devices, marketing products that added features but did not lessen growing discrepancies in product-to-product performance capabilities

Home oxygen therapy, once an area with a relatively fixed amount of therapeutic options, now has a widely variable product base that has created noteworthy misunderstanding and uncertainty as to the potential effectiveness of different products. Only now is there becoming wider awareness that a " 2 " on one device is not the same as " 2 " on another, let alone not equivalent to $2 \mathrm{~L} / \mathrm{min}$ continuous flow.

\section{Home Oxygen Prescriptions}

The assessment of clinically effective LTOT is best achieved by the patient simulating their home activities with the proposed oxygen equipment. The home oxygen prescription requires detailed instructions on the dose of oxygen the patient will have need of at all activity levels and the oxygen equipment required to accomplish normal activities within and outside their home. An option to traditional prescriptions for home oxygen therapy would be to have the prescription indicate an oxygen saturation level to be achieved at all activity levels, with the home oxygen provider charged with accomplishing this objective. The physician will need to be actively involved to ensure the patient is receiving the prescribed therapy. Patient needs will change throughout the course of the disease, and both the patient's oxygen requirements and the oxygen equipment capabilities will need to be monitored to ensure effective and consistent therapy. Initial needs for oxygen may be only required with exercise and sleep, then progress to 24 hour therapy, so flexibility of sourcing an effective device is necessary. Patient oxygen demands may change as the disease progresses, so options for a higher dosing product to ensure patient benefits at all activity levels outside the hospital are required. Equipment should be available to the home patient based on clinical needs and not reimbursement constraints.

Technology has evolved to the point where a specific amount of oxygen can be delivered per breath, allowing for the prescribing physician to identify a dose of oxygen as opposed to a flow. Current technology is limited in maximum dose capabilities and oxygen purity, yet technology can and should be developed to accomplish the objective of dose volume and oxygen purity to meet the patient's clinical needs at all activity levels.

\section{Patient Assessment}

Patients requiring LTOT should be assessed by the prescribing physician for the proper oxygen dose at all ac- tivity levels and to identify a home oxygen product that can accomplish the prescription. There are no standards for the titration of a patient for home oxygen therapy, so a standard should be developed. The 6-min walk test is well established, yet is conducted to determine conditioning, not oxygen prescriptions. Currently, clinicians indicate that they have titrated the patient for LTOT, yet without a standard of titration, the prescriptions can vary from one clinician to another. Professional medical societies should develop a standard of titration for home oxygen patients.

\section{Oxygen Metering}

Standardized labeling of intermittent-flow devices is needed to help improve metering of oxygen from home oxygen devices. Intermittent flow is not equivalent to continuous flow, so the labeling of oxygen delivery device should not refer to the devices as such. Intermittent flow can reflect a specific dose of oxygen per breath, based on a determined inspiratory time. Professional medical societies should focus on establishing a recommendation based on the best therapeutic option for the patient. At this time, equipment has been developing with a broad range of dosing capability. Labeling of existing equipment may need to change once a recommendation is established.

\section{Recommendations}

The many options for home oxygen therapy equipment and the variability in performance capabilities of new devices require a new course of action by clinicians to address a growing problem in home oxygen therapy related to effective clinical care, equipment selection, and reimbursement for products and services. Recommendations for action needed:

- Physicians should be involved in the development of LTOT programs and products that are capable of meeting the patient's needs for effective oxygen therapy at all activity levels outside the hospital. This would include setting standards for the assessment of patients requiring LTOT, standards for the titration of LTOT at specific intervals to meet the needs at all activity levels, active involvement in requesting performance specifications for new and existing LTOT products, and standards for ongoing monitoring and assessment of patients receiving LTOT.

- Labeling of the metering devices used with LTOT should include oxygen flow with a clinically acceptable $\mathrm{F}_{\mathrm{IO}_{2}}$ range. Dose volume for intermittent-flow devices should be labeled based on calculated volume for the first half of inspiration, in $\mathrm{mL}$, with the volume delivered in a breathing frequency range identified for specific breathing frequencies from 15 to 40 breaths/min. 
- Oxygen purity monitoring should be available for all oxygen concentrator devices. Alarms should initiate at concentrations below $85 \%$ purity for $>5 \mathrm{~min}$. For POC devices, alarms should initiate at breathing frequencies that produce oxygen purity below $85 \%$.

- A new titration standard for oxygen prescriptions at all activity levels should be developed by professional medical societies for patients receiving LTOT, to ensure adequate patient oxygenation with the devices provided.

- Prescriptions and therapy for LTOT should focus on patient outcomes with oxygen saturations greater than $90 \%$ at all activity levels, rather than the process of home oxygen equipment set-up and maintenance. Prescriptions should allow for a titration to a specific saturation at all activity levels.

- Appropriate and targeted reimbursement for RT professional service in the home is required to ensure that effective LTOT is provided. The RT would assist the physician by ensuring appropriate oxygen therapy objectives are met, using equipment that provides effective patient oxygenation at all activity levels. RTs should be recognized and reimbursed for services in the home, in addition to the reimbursement given for the equipment provided.

- Reimbursement for home oxygen equipment should reflect the cost of both products and services related to the effective deliver of the drug oxygen. Stationary concentrators have the lowest product and service costs, and light-weight, longest lasting portable systems have the highest product and service costs. Reimbursement should reflect these differences.

\section{Summary}

There are many equipment options available for home oxygen therapy to meet the needs of the LTOT patient. Equipment variability in oxygen storage, oxygen production from concentrators, oxygen dosing from metering devices, and operating times for portable oxygen systems has created a need for clear labeling of an oxygen product's capabilities, applications, and limitations. Clinician and patient education is required to ensure the proper use and application of home oxygen equipment.

Patients must be tested on the equipment they will use in the home at all activity levels, to ensure adequate oxygenation and benefits from the home oxygen therapy. Patients must be monitored frequently for changes in clinical needs and equipment capabilities to meet those needs throughout their lifetime use of home oxygen therapy. A new patient assessment and titration procedure is required to reflect and simulate the multitude of activity levels found in the home, to ensure oxygen equipment capabilities to effectively oxygenate the patient to improve clinical outcomes and patient adherence to the prescribed therapy. New oxygen therapy products and procedure should be validated through research and peer reviewed publication.

Physicians should be actively involved in the LTOT process to ensure complete assessment of a patient's oxygen therapy needs, including patient titration, prescription, and monitoring of effective patient oxygenation at all activity levels throughout the course of the patient's disease.

\section{REFERENCES}

1. American Association for Respiratory Care. AARC Clinical Practice Guideline. Oxygen therapy in the home or alternate site health care facility: 2007 revision and update. Respir Care 2007;52(1):1063-1068.

2. Kacmarek RM. Delivery systems for long-term oxygen therapy. Respir Care 2000;45(1):84-92.

3. Dunne PJ. The clinical impact of new long-term oxygen therapy technology. Respir Care 2009;54(8):1100-1111.

4. Strickland SL, Hogan TM, Hogan RG, Sohal HJ, McKenzie WN, Petroski GF. A randomized multi arm repeated measures prospective study of several modalities of portable oxygen delivery during assessment of functional exercise capacity. Respir Care 2009;54(3): 344-348.

5. Dunne PJ. New long-term oxygen therapy technology: the transition continues (editorial). Respir Care 2008;53(9)1163-1165.

6. Petty TL. Historical highlights of long-term oxygen therapy. Respir Care 2000;45(1):29-36.

7. Stark RD, Bishop JM. New method for oxygen therapy in the home using an oxygen concentrator. BMJ 1973;2(858):105-106.

8. Problems in prescribing and supplying oxygen for Medicare patients. Summary of a Conference on Home Oxygen Therapy held in Denver, February 28 and March 1, 1986. Am Rev Respir Dis 1986; 134(2):340-341.

9. Bolton CE, Annandale JA, Ebden P. Comparison of an oxygen concentrator and wall oxygen in the assessment of patients undergoing long term oxygen therapy assessment. Chronic Respir Dis 2006;3(1):49-51.

10. Dheda K, Lim K, Ollivere B, Leftley J, Lampe FC, Salisbury A, et al. Assessments for oxygen therapy in COPD: are we under correcting arterial oxygen tensions? Eur Respir J 2004;24(6):954-957. Erratum in: Eur Respir J 2005;25(4):773.

11. Christopher KL, Porte P. Long-term oxygen therapy. Chest 2011; 139(2):430-434.

12. Rice KL, Schmidt MF Buan JS, Lebahn F, Schwarzrock TK. Ac$\mathrm{cuO}_{2}$ oximetry-driven oxygen conserving device versus fixed dose oxygen devices in stable COPD patients. Respir Care 2011;56(12): 1901-1905.

13. Cirio S, Nava S. Pilot study of a new device to titrate oxygen flow in hypoxic patients on long term oxygen therapy. Respir Car 2011; 56(4):429-434.

14. Petty TL. Home oxygen: a revolution in the care of advanced COPD. Med Clin North Am 1990;74(3):715-729.

15. Petty TL. Supportive therapy in COPD. Chest 1998;113(4 Suppl): 256S-262S

16. Ries AL, Bauldoff GS, Carlin BW, Casaburi R, Emery CF, Mahler DA, et al. Pulmonary rehabilitation. Joint ACCP/AACVPR evidencebased clinical practice guidelines. Chest 2007;13(Suppl 5):4S-42S

17. Continuous or nocturnal oxygen therapy in hypoxemic chronic obstructive pulmonary disease: a clinical trial. Nocturnal Oxygen Therapy Trial Group. Ann Intern Med 1980;93(3):391-398.

18. Petty TL, Bliss PL. Ambulatory oxygen therapy, exercise and survival with advanced chronic obstructive pulmonary disease: the Nocturnal Oxygen Therapy Trial revisited. Respir Care 2000;45(2):204-211. 


\section{Options For Home OXYGEN THERAPy EQUIPMENT}

19. Palwai A, Skowronski M, Coreno A, Drummond C, McFadden ER Jr. Critical comparisons of the clinical performance of oxygen conserving devices. Am J Respir Crit Care Med 2010;181(10):1061-1071.

20. McCoy RW. Oxygen conserving techniques and devices. Respir Care 2000;45(1):95-103.

21. Stoller JK, Panos RJ, Krachman S, Doherty DE, Make B. Oxygen therapy for patients with COPD: current evidence and the LongTerm Oxygen Therapy Treatment trial. Chest 2010;138(1):179-187.

22. Carlin BW. Pulmonary rehabilitation and chronic lung disease: opportunities for the respiratory therapist. Respir Care 2009;54(8):10911099.

23. Boatright J, Ward JJ. Therapeutic gases: manufacture, storage, and delivery. In: Hess DR, MacIntyre NR, Mishoe SC, Galvin WF, Adams $\mathrm{AB}$, editors. Respiratory care principles and practice, 2nd edition. Jones \& Bartlett; 2012:282.

24. Valley Inspired Products. 2007 guide to oxygen conserving devices. Apple Valley, MN; 2007.

25. Block AJ. Intermittent flow oxygen devices: technically feasible, but rarely used (editorial). Chest 1984;86(5):657-658.

26. McCoy RW, Limberg T. Evaluation of a novel device to titrate portable oxygen systems (abstract). Respir Care 2007;52(11):1620. http://www.rcjournal.com/abstracts/2007/?id=aarc07_177. Accessed October 25, 2012.
27. Shigeoka JW. The current status of oxygen conserving devices (editorial). Respir Care 1985;30(10)833-836.

28. Long term domiciliary oxygen therapy in chronic cor pulmonale complicating chronic bronchitis and emphysema. Report of the Medical Research Council Working Party. Lancet 1981;1(8222):681-686.

29. Pflug AE, Cheney FW Jr, Butler J. Evaluation of an intermittent oxygen flow system. Am Rev of Respir Dis 1972;105(3):449-452.

30. McCoy RW, Carlin B. product performance variability with home portable oxygen systems may impact patient performance outcomes (editorial). Respir Care 2009;54(3)324-326.

31. Pierson DJ. Pathophysiology and clinical effect of chronic hypoxia. Respir Care 2000;45(1):39-51.

32. Bliss PL, McCoy RW, Adams AB. Characteristics of demand oxygen delivery systems: maximum output and setting recommendations. Respir Care 2004;49(2):160-165.

33. Chatburn RL, Williams TJ, Performance comparison of 4 portable oxygen concentrators. Respir Care 2010;55(4):433-442.

34. Further recommendations for prescribing and supplying long term oxygen therap. Summary of the second conference on long term oxygen therapy held in Denver, CO, December 11-12, 1987. Am Rev Respir Dis 1988;138(3):745-747.

35. Petty TL, Doherty DE. Recommendations of the 6th long-term oxygen consensus conference. Respir Care 2006;51(5):519-525.

\section{Discussion}

Branson: When we started evaluating oxygen concentrators and pulsedose for use in mechanical ventilation, we observed what you described so nicely in your presentation: that every device gives a different bolus size of oxygen with the same setting of 3 . Should these devices have a number setting or the actual dose size?

McCoy: Dose volume would be best, but it is variable based on breathing frequency and other variables. The standards organization, ASTM International [formerly American Society for Testing and Materials], is trying to address that, but they haven't reached consensus because of the many variables that impact dose volume. We need to know what the dose volume is in the range of inhalation, because, though we say $60 \%$ of the inhalation is where the therapeutic dose should be, is that really true, or is it $50 \%$ or $70 \%$ ? Yes, we need to have milliliters per pulse, but it needs to be categorized so we know what the variables are.
Branson: In my understanding, the device will either give a constant volume no matter what, and if the breathing frequency is high, the purity or the $\mathrm{F}_{\mathrm{IO}_{2}}$ will fall, or the purity will stay the same and the pulse volume will fall. The final option is that the device will skip 2 out of 3 breaths, in which case the real delivered oxygen, $\mathrm{F}_{\mathrm{DO}_{2}}$ not the $\mathrm{F}_{\mathrm{IO}_{2}}$-would be unknown. But none of that is really important, as long as $\mathrm{S}_{\mathrm{pO}_{2}}$ is the target. I have a penchant for thinking closed loop is better, and I don't see why that technology isn't used and hasn't become the standard of care.

McCoy: Because of cost. Nobody's paying for that, and nobody's asking for it either. If all the physicians say, "I want a saturation-controlled $\mathrm{O}_{2}$ delivery system," what home care provider is going to deliver that system? If the decision becomes either meet the physician's request or provide business as usual, then it becomes who wants the business? Payers will need to pay for closed loop technology for it to be accepted. If the physicians mandate saturation controlled oxygen de- livery, and effective $\mathrm{O}_{2}$ therapy becomes a standard of care by ensuring oxygenation at all activity levels, then no one will have a choice except to provide effective oxygen therapy. When we say the payers are driving the business, it's sort of like saying the payers are practicing medicine, so why don't we let them have the liability of the consequences of ineffective therapy? If no one is going to pay for effective therapy, the physicians can still prescribe it and let someone else deal with the consequences: not the physicians.

Mangus:* With all the variables and issues about which piece of equipment does what, and what the RT knows, and what the physician knows, and the fact that we can't seem to get everybody together ... it is a huge body of information to try to absorb, synthesize, and carry with you. The simple solution that is immediately available and economical is "titrate to saturate." Patients should have—and I

\footnotetext{
* Mark W Mangus Sr RRT RPFT FAARC, Inova Labs, Austin, Texas.
} 
know I'm preaching to the choirpulse oximeters, and they should use them, just like diabetics use glucometers, to monitor a drug that will kill them a lot more surely than $\mathrm{O}_{2}$ ever could, and that would take care of a lot of the issues of which device is better. It puts it back to the device that's best for a patient is the one that works.

McCoy: A lot of physicians won't prescribe an oximeter.

Mangus: From the few surveys that have been done, I think RTs are resistant too. The resistance is greater than half on both sides.

McCoy: The other issue is knowing what you're giving, because titrating to saturation, when you hit the highest number on your $\mathrm{O}_{2}$ concentrator, you need to know whether there's another device out there that can go higher. If you're on the maximum setting on one device, you need to know whether you can go higher on another device.

Mangus: Because across the breadth of all portable $\mathrm{O}_{2}$ systems today and the delivery technology we have, there are points at which individual patients, depending on the severity of their disease and their hypoxia, will reach the maximum capability of a given device or perhaps of the maximally capable device available to them. And they need to know when to sit and recover or modify their activities. And a pulse oximeter allows them to do that.

Lewarski: $\dagger \quad$ I think the intermittentflow or pulse-dosing devices basically fall into the same category as other low-flow $\mathrm{O}_{2}$ delivery devices, which by design are highly variable. Having been involved in designing and testing such devices, from a design stand-

$\dagger$ Joseph S Lewarski RRT FAARC, Invacare, Elyria, Ohio. point there is no bolus number to pick that's always right and a match to a continuous-flow setting. In a nasal cannula, continuous-flow comparison, if I evaluated 100 different patients with 100 different breathing patterns, tidal volumes, breathing frequencies, inspiratory-expiratory ratios, dead space, et cetera, the net effective $\mathrm{O}_{2}$ delivery and $\mathrm{F}_{\mathrm{IO}_{2}}$ would be different for each patient. We could pick one number for each setting on all pulsedose devices, and, like a broken watch, it would be right at some point in time-meaning a perfect dose match at some given breathing pattern for nearly all patients.

I believe that the use of intermittent flow or pulse flow devices, and the more stringent oxygenation evaluations often associated with their use, have revealed some of the $\mathrm{F}_{\mathrm{IO}_{2}}$ variability weaknesses that have long existed in low-flow devices. If you go back to the early LTOT consensus conferences, the titrate to saturate concept was introduced long before the use of pulse-dosing devices, simply because of the known variability in breathing patterns and oxygen demand with exercise and sleep. Some studies found $40-50 \%$ of all continuous-flow patients desaturating at night on their continuous flow, largely because of changes in their nocturnal breathing patterns. There are probably about 35 published clinical studies - though not all large or randomized and controlled, and often with different devices - and I haven't seen one that suggested that you can't adequately oxygenate a patient with a conserving device or a pulse-dosing device, as long as it's appropriately titrated.

I think there is too much emphasis and blame on the equipment. The ISO [International Organization for Standardization] and the ASTM are moving toward standardized labeling and definitions for this class of device. Simple standardization of device performance would be difficult if not impossible at this time, as there are intellectual property rights around these devices, which would make it nearly impossible to go back and make them all do exactly the same thing. The ISO is working to standardize terms and definitions, but taxonomy has had a problem, even in mechanical ventilation.

I saw that Chatburn's old article ${ }^{1}$ on the topic was revisited, arguing that we don't use the same terms or describe features and functions the same way when it comes to the technology that exists in these devices. I think the end result here will be a titrate to saturate standard of care, which will arrive either through the legislative process or part of the prescription/ certificate of medical necessity process. Most clinicians believe it is ultimately what's necessary.

The opposition to letting patients have their own oximeters is an old mentality that may have been driven by many RTs, as we often think of pulse oximetry as a lab procedure. This was historically associated with the reimbursement and CPT [Current Procedural Terminology] coding rules, most of which are not relevant today. Many oxygen patients aren't waiting for us, and they often purchase their own oximeters on the Internet or through their homecare company, so I think we would be better off prescribing them. The use of an oximeter in managing LTOT is frequently compared to managing an insulin dependent diabetic patient with a glucometer. I admit, 10 years ago I wasn't sure that giving patients pulse oximeters was a good thing, but now I think it's necessary. It goes to Bob's earlier points about needing more physician involvement. Pulmonologists probably write less than $10 \%$ of the prescriptions for $\mathrm{O}_{2}$ in the United States: it's primarily a primary care physician function.

Branson: Joe, I think worrying about the $\mathrm{F}_{\mathrm{DO}_{2}}$ in a low-flow is a copout. I'm not saying everything needs to do the same thing, but if I take 3 of these devices and they all have set- 
tings of 1,2 , and 3 , and I know one device can make only $500 \mathrm{~mL} / \mathrm{min}$ and the other one can make $1,000 \mathrm{~mL} / \mathrm{min}$, then the " 3 " setting is very different. I agree that the issue is the labeling so that users understand it. Because right now what they think is that 3 on this one is the same as 3 on that one, and that it's equivalent to $3 \mathrm{~L} / \mathrm{min}$ from a wall flow meter in the hospital, but it's not.

Lewarski: Agreed. Proponents of standardized labeling for these devices want the dose and other key characteristics labeled, such as the trigger sensitivity, trigger response time, and total bolus delivery time, because these devices operate much more like an assist device than a simple flow valve. They sense breathing via pressure drop, trigger in response, and deliver an $\mathrm{O}_{2}$ bolus at some flow rate. All flow is volume, and the device is simply converting flow to volume, delivered in bolus form. How they do this may vary by device, but if you understand the key performance variables when looking at the labels and you're educated on the device, then you're going to know if a particular device has a greater probability of delivering the $\mathrm{F}_{\mathrm{IO}_{2}}$ and $\mathrm{F}_{\mathrm{DO}_{2}}$ you want.

So I completely agree. I also believe you're going to see those specification disclosures, whether they are voluntary or forced through ISO and ASTM. The ISO regulation for conservers is currently being updated, and there is a lot of language around specification disclosure and labeling.

McCoy: The unfortunate thing is that there aren't physicians there, either.

Lewarski: The unfortunate thing is that not many people on the ISO standards committee are experts on oxygen and conserving devices.

McCoy: If it's not medically driven, it's not going to come out the way we want it to. Another option is the high- dose capability from intermittent-flow devices that could address your emergency medical services standpoint. We've never looked at doing a highdose delivery from an intermittentflow device, so we could have a dose volume of $200 \mathrm{~mL}$ or more and provide gas like a little ventilator and give an $\mathrm{F}_{\mathrm{IO}_{2}}$ of 0.6 to 0.8 just by giving them that high a dose, which could bring the concept of intermittent-flow back into the hospital to get it accepted and be translated back into the home. So at least we'd be comparing apples to apples.

Pierson: $\$$ You mentioned patients being on home $\mathrm{O}_{2}$ therapy for an average of about 11 months before they die. I've heard that figure for more than 20 years; I think I heard it at the first oxygen consensus conference, ${ }^{2}$ from one of the home care folks. You also mentioned that now we are putting people on $\mathrm{O}_{2}$ earlier and they're living longer and therefore using it longer. My question for you is, do you have data for either of those statements?

\section{McCoy: Joe would.}

Lewarski: Actually, the government did it for us. In 2006 the Office of the Inspector General published a report on home oxygen, which included data on Medicare $\mathrm{O}_{2}$ patient stay from months 1 through 36 . This was derived from claims data, so we're not really looking at patient-specific information to see what the medical outcome was, such as prolonged hospitalization or death. Instead, we are looking at Medicare claims data from the oxygen start date until the claim for services ended, meaning that the patient was no longer on $\mathrm{O}_{2}$. In that study the median stay on home $\mathrm{O}_{2}$

\$ David J Pierson MD FAARC, Emeritus, Division of Pulmonary and Critical Care Medicine, Harborview Medical Center, University of Washington, Seattle, Washington. was about 10.5 months, and the percentage of patients who that stayed on therapy for 3 years was approximately $22 \%$. The published data was limited to a 36-month review, although it has been estimated that about 5-8\% of the patients were still on $\mathrm{O}_{2}$ at the 5-year point, which is a milestone from the payer perspective, because it is when they start reimbursing again.

What's interesting is that the decay curve is very steep in the first 6 months. There are a large number of patients coming off of $\mathrm{O}_{2}$ after relatively short periods of use, within that first 6-12 months. It is not clear whether these data correlate to past beliefs about stay for late-stage $\mathrm{O}_{2}$ patients or it reflects changes in $\mathrm{O}_{2}$ stay for earlier stage patients with acute-onchronic disease and a short-term need for $\mathrm{O}_{2}$. Late-stage patients may be expiring after short periods of use, and patients with acute medical issues may improve to a stable, normoxic baseline at the time of follow-up with their physician. We don't know the specifics, but we know the claims stop, and there is a high churn rate in the first 11 months.

Pierson: Are you saying that we now have data to substantiate Bob's comment that we are placing people with COPD on home $\mathrm{O}_{2}$ therapy earlier and they're on it longer?

\section{Lewarski: No.}

Pierson: Or is this just a more comprehensive set of data to substantiate his original statement from some time in the past?

Lewarski: I don't know the deeper meaning of these data, other than that there is a regression curve or decay curve representing the stay on oxygen from start to 36 months. It also clearly identifies that median stay was just shy of 11 months, demonstrating that half of Medicare patients started on $\mathrm{O}_{2}$ will be off by the 11th month, and the remaining half will stay on for longer periods, 
with continued attrition over time. The purpose of the study was not clinical: it was to identify the number of Medicare $\mathrm{O}_{2}$ patients who will still be on service when the payment caps at 36 months. The government wanted to know what the financial liability would be post the 36-month cap period. That's where the $22 \%$ comes from, which was the number still on rental at month 36 . Whether or not this information correlates to what we thought earlier about stay and survival, I don't know.

Mangus: I would suggest the data may be there, in the same manner Joe has described, but we probably have to go back and look between 1990 and 1995, around the time that, because some pulmonary rehabilitation programs were seeing so many patients who did not desaturate at rest and did not therefore previously qualify for $\mathrm{O}_{2}$ therapy, but were found to desaturate (in many cases profoundly) during exercise. And by pushing Medicare we got them to modify the "at rest" requirement to exhibit saturation of $88 \%$ or less and to start allowing patients who demonstrated exertional desaturation or even sleep desaturation or the combination to qualify for $\mathrm{O}_{2}$. I would think that before then we'd have more data statistically looking at claims of patients who were at-rest desaturating, representing the sicker ones, and then we'd be able to see the group coming in with earlier use in that era and we might be able to glean some kind of results from there and see if there's an uptick.

Kallet: It seems that if you start people earlier, then, ipso facto, they're going to survive longer! How much of that is cause and effect?

Lewarski: I don't know how this data translates clinically. I just know how long they are receiving oxygen services in the home. That's all I can say about the data. Anything beyond that is opinion and theory.
Criner: I agree. To totally capsulize the patient's activities at home to assess their real $\mathrm{O}_{2}$ needs would be desirable. But how do you do that? There are some data where they simulated in the lab the home circumstances in which they are more likely to desaturate at lower levels doing some types of home activities than they would with other types of home activities, but how would you assess that? The second thing would be the problem of adherence in the home, and not being reimbursed, and the RTs can't get paid for going there. Are there data that show patients present to the hospital or have an untoward response because they didn't use their $\mathrm{O}_{2}$ correctly or failed to use their $\mathrm{O}_{2}$ ? Are there any claims data to substantiate that? And what do you think the future will be for using technology to better assess the patient's compliance and adherence at home, and who would monitor that?

McCoy: I would suggest the use of 24-hour oximetry. If we can get a patient to wear an oximeter for 24 hours, we could assess their oxygenation. Next, we could have a patient do their daily activities at their prescribed level and encourage the patient to adhere to their $\mathrm{O}_{2}$ because we're doing a test. A 24-hour window that reflected the patient's normal activity might be able to identify the dips in oxygen saturation and help us in prescription and device selection. But since no one pays for this level of patient assessment, no one does it.

Criner: How would you assess them right now in your practice? How do you make sure they're optimally treated for their daily activities? Do you ask them, or do you mimic a home scenario in the lab?

McCoy: It takes less of a scientific approach, and I think the people who go into the home know this. When you talk to a non-adherent patient and ask why they're not using it more, you hear answers such as, "It's too heavy," or, "The cannula hurts my nose," or "I don't feel any better with it." You try to find out their reasons for not adhering, and many times, to encourage adherence, you tell the patient, "You have to use your oxygen," but, instead, if you take the approach of asking why they aren't using it and seeing if it's something you can change, you can do that and the benefits are fantastic.

What do we know about readmission? There are some data about the readmission rate of COPD patients, especially with the rehospitalization problem. I think in western Pennsylvania one of the home care companies was monitoring the data and had about a 35\% COPD patient readmission. I don't know if that's $\mathrm{O}_{2}$-dependent, but if you've got $35 \%$ coming back to the hospital in the first 30 days, that's a big threat for a penalty from CMS [Centers for Medicare and Medicaid Services]. So what this home care company is doing is reinvesting in having RTs and technology. They've changed focus from what CMS is paying, and are looking to what the future's going to be, so they're investing in RTs and technology to oxygenate the patients, really targeting the $\mathrm{O}_{2}$, and they've shown a 7 or $8 \%$ reduction in readmission. Just by doing professional respiratory care with therapy as the end point, as opposed to procedural dropping equipment off.

Hess:§ I'll be a bit of a contrarian. On the one hand it sounds very attractive to give patients pulse oximeters and allow them to titrate their $\mathrm{O}_{2}$ to their $\mathrm{O}_{2}$ saturation, but it may not be so simple. Here's one of my concerns. Imagine a patient with COPD who's early in an exacerbation and their $\mathrm{P}_{\mathrm{CO}_{2}}$ is rising and their $\mathrm{O}_{2}$ saturation is drop-

$\S$ Dean R Hess PhD RRT FAARC, Editor in Chief, RESPIRATORY CARE, and Department of Respiratory Care, Massachusetts General Hospital, Harvard School of Medicine, Boston, Massachusetts. 
ping. So maybe the prudent thing would be not be to turn up the $\mathrm{O}_{2}$ but to call the doctor or go to the emergency department. Or, to go back to Bob Owens's talk, the patient is desaturating at night because they' re having OSA [obstructive sleep apnea], and the prudent thing may not be to turn up the $\mathrm{O}_{2}$ but to put the patient on CPAP. I'd be a little careful before saying that every patient at home on $\mathrm{O}_{2}$ really needs a pulse oximeter, until we think through that carefully.

Lewarski: I'd like to support Dean's comments. One of the questions I keep asking about closed loop feedback models, and a lot of what I call "micro-titration" of LTOT, is that nearly everything we know about LTOT outcomes is based on the Nocturnal Oxygen Therapy Trial and the Medical Research Council study and using $\mathrm{O}_{2}$ for 17 or more hours a day, which was considered good adherence. The patients in these studies were off oxygen a good chunk of the day, and, based on their study entrance criteria, were moderately or severely hypoxemic on room air. In the benchmark research, patients would likely experience moderate to severe hypoxemia about $30 \%$ of the day. In that population, is a short, mild desaturation clinically relevant?

If the patient walks across a parking lot and has a mild desaturation from the mid-90s to 89, and they stop and recover, then start strolling at their normal rate without additional desaturations, is that a clinically relevant desaturation for a patient with chronic lung disease? Would responding to that, or potentially over-responding and making a patient wear an oximeter 24/7, change outcomes? I don't think we know the answers, but I wonder if it's overkill. Right now we're fighting with them just to wear their $\mathrm{O}_{2}$ or nasal cannula at least those 17 hours a day, and especially when they ambulate. I'm not sure that we know enough about lifestyle, ambulation, and $\mathrm{O}_{2}$ therapy as a whole to make this leap simply because we have some technology available. I don't think it should be about reimbursement, but, instead, whether this technology is the right approach.

Jeff Ward: I'll reinforce Dean's comment. There's a very good prospective randomized controlled trial by John Downs's group that showed that supplemental $\mathrm{O}_{2}$ impedes detection of hypercapnia in the post-anesthesia recovery area. ${ }^{3}$ This is even more of a problem outside the high caregiver/ patient ratio area of the post-anesthesia recovery unit, such as the hospital floor or the patient's home. Perhaps the increased emphasis on waveform capnography in the newest American Heart Association guidelines for cardiopulmonary resuscitation ${ }^{4}$ will improve both awareness and technology.

McCoy: There is a correlation in the sleep industry. In an overnight sleep study, if a patient desaturates for 10 seconds, that's an event. And if you have 10 events, you have an RDI [respiratory disturbance index] of 10 . We throw CPAP on very fast for very minimal desaturations. If we aggressively attack desaturations for very short periods in a sleeping patient, shouldn't it be the same with a COPD patient with comorbidities kicking in? Shouldn't the rationale for sleep be the same as for any other disease?

Hess: I don't know that we can say that.

Claure: Sort of in defense of monitoring, I don't think the knowledge of the information obtained by the monitors is bad for your patients. Learning how often or how severe is the hypoxemia or the hyperoxemia in an individual patient or in a group of patients may be important. The key is what you do with the information. Having a very sick patient titrating his or her own $\mathrm{O}_{2}$ may not be the best use of monitors, but at least finding out how the patient's oxygenation is during the day or night and over time may be important.

1. Chatburn RL, Mireles-Cabodevila E. Closed-loop control of mechanical ventilation: description and classification of targeting schemes. Respir Care 2011;56(1): 85-102.

2. Problems in prescribing and supplying oxygen for Medicare patients. Summary of a Conference on Home Oxygen Therapy held in Denver, February 28 and March 1, 1986. Am Rev Respir Dis 1986; 134(2):340-341.

3. Fu ES, Downs JB, Schwiger JW, Miguel RV, Smith RA. Supplemental oxygen impairs detection of hypoventilation by pulse oximetry. Chest 2004;126(5):1552-1558.

4. Neumar RW, Otto CW, Link MS, Kronick SL, et al. Part 8: Adult advanced cardiovascular life support. 2010 American Heart Association guidelines for cardiopulmonary resuscitation and emergency cardiovascular care science. Circulation 2010; 122(Suppl):S729-S767.

This article is approved for Continuing Respiratory Care Education credit. For information and to obtain your CRCE

(free to AARC members) visit

www.rcjournal.com

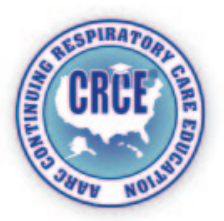

